\title{
The Effect of Aging on Experience-Dependent Plasticity of Hippocampal Place Cells
}

\author{
Jiemin Shen, ${ }^{4}$ Carol A. Barnes, ${ }^{1,2,4}$ Bruce L. McNaughton, ${ }^{1,3,4}$ William E. Skaggs, ${ }^{4}$ and Karen L. Weaver ${ }^{1,4}$ \\ ${ }^{1}$ Departments of Psychology, ${ }^{2}$ Neurology, and ${ }^{3}$ Physiology, and ${ }^{4}$ Arizona Research Laboratories, Division of Neural \\ Systems, Memory and Aging, University of Arizona, Tucson, Arizona 85724
}

The firing characteristics of $1437 \mathrm{CA} 1$ pyramidal neurons were studied in relation to both spatial location and the phase of the theta rhythm in healthy young and old rats performing a simple spatial task on a rectangular track. The old rats had previously been found to be deficient on the Morris spatial learning task. Age effects on the theta rhythm per se were minimal. Theta amplitude and frequency during rapid eye movement sleep were virtually identical. During behavior, theta frequency was slightly reduced with age. In both groups, cell firing occurred at progressively earlier phases of the theta rhythm as the rat traversed the place field of the cell (i.e., there was "phase precession," as reported by others). The net phase shift did not differ between age groups. The main finding of the study was a loss of experience-dependent plasticity in the place fields of old rats. During the first lap around the track on each day, the initial sizes of the place fields were the same between ages; however, place fields of young rats, but not old, expanded significantly during the first few laps around the track in a given recording session. As the place fields expanded, the rate of change of firing with phase slowed accordingly, so that the net phase change remained constant. Thus changes in field size and phase precession are coupled. A deficit in plasticity of place fields in old rats may lead to a less accurate population code for spatial location.

Key words: aging; hippocampus; place fields; phase precession; theta rhythm; plasticity
Because effective spatial learning requires an intact hippocampus (e.g., O'Keefe and Nadel, 1978; Morris et al., 1982; Sutherland et al., 1982; Barnes, 1988; Jarrard, 1993), and because this crucial cognitive function is significantly impaired during normal aging, the study of how neuronal information processing in the hippocampus is altered with age is of considerable interest. In rodents, age deficits are observed in a variety of spatial learning and memory tasks (Barnes, 1979; Wallace et al., 1980; deToledoMorrell et al., 1984; Gage et al., 1984; Barnes and McNaughton, 1985; Gallagher et al., 1985; Gallagher and Pelleymonter, 1988). These effects cannot be fully accounted for by sensory or motor deficits (Rapp et al., 1987; Gallagher and Pelleymonter, 1988; Gage et al., 1989), suggesting that alterations in hippocampal function with age may contribute to their etiology. There are three particularly striking aspects of hippocampal electrophysiology that have attracted interest with respect to their possible roles in spatial learning, and the change with age of which could contribute to age-associated memory impairment: place-specific firing (O'Keefe and Dostrovsky, 1971) of single neurons ("place cells"); the 7-12 Hz theta rhythm in the EEG (Green and Arduini, 1954), which is tightly related to "spatial" behaviors (e.g., walking and rearing) (Vanderwolf et al., 1975); and the longlasting change in synaptic efficacy that can be induced by patterned activation of hippocampal afferents [i.e., long-term poten-

Received March 19, 1997; revised May 21, 1997; accepted June 13, 1997.

This work was supported by National Institutes of Health and National Institute of Mental Health Grants AG12609 and MH01227. We thank M. Suster, R. D’Monte and J. L. Gerrard for help with constructing the hyperdrive, animal training, and recording, M. R. Mehta for helpful insights into data analysis strategies, and A. Treves for useful discussion.

Correspondence should be addressed to Dr. Carol A. Barnes, Life Sciences North Building, Room 384, University of Arizona, Tucson, AZ 85724

Copyright (C) 1997 Society for Neuroscience $0270-6474 / 97 / 176769-14 \$ 05.00 / 0$ tiation (LTP)] (Bliss and Gardner-Medwin, 1973; Bliss and Lømo, 1973).

Unfortunately, the available data on the effects of age on these phenomena are somewhat contradictory, and it remains unclear whether there are age differences in the theta rhythm (Barnes, 1979; Forbes and Macrides, 1984; Markowska et al., 1995) or whether or how place field characteristics change in old rats (Barnes et al., 1983; Mizumori et al., 1996; Markus et al., 1994). Several factors may contribute to the variability of the results of previous studies of age effects on place field characteristics of old rats. A major one is the age of the animals at the time of recording. It is becoming increasingly clear that age effects on the nervous system in general are accelerated late in the lifespan and hence may not show up until the last months of life. Secondly, Mizumori et al. (1996) have reported an interaction between age and the spatial task used during recording on the quality of place fields. Thus, age effects may not show up in all tasks or may be expressed differently in different tasks. Third, different studies have used different statistical methods. Of particular importance is the necessity of performing statistics on a per animal rather than a per cell basis. Because cells within an animal are not independent, the latter practice can lead to the detection of effects that are attributable to normal between-subject variation and that are not necessarily consistent effects of age per se. Finally, the quality of single-unit isolation and number of cells recorded in a given study may influence the power to detect quantitative changes in place field characteristics with age. In the present study, improved isolation of hippocampal units was accomplished using multiple "tetrode" probes (McNaughton et al., 1983b; O’Keefe and Recce, 1993; Wilson and McNaughton, 1993), and statistical analysis was conducted by animal rather than by cell. The discrepancy in the literature concerning changes in hippocampal EEG during aging could be attributed to differences in 
the extent and velocity of locomotion of animals of different ages. Because the frequency of the theta rhythm increases with running velocity (McFarland et al., 1975; Arnolds et al., 1979; Recce, 1994), age differences in running speed could account for "slowing" in frequency with age. In the present experiment, this parameter was controlled for.

The effects of age on two recently discovered characteristics of hippocampal dynamics were of particular interest in the present study. First, Mehta et al. (1997) have demonstrated a rapid, experience-dependent expansion of place fields in young rats during repeated performance of a route-following task. It was of interest to determine whether this process is altered by age. Second, although it has been known that single hippocampal neurons are periodically modulated at the theta frequency (Ranck, 1973; Fox et al., 1986), O'Keefe and Recce (1993) recently found that place cell firing advances gradually in phase as the rat passes through the place field (Fig. 1). They called this effect "phase precession." Thus, the cell-firing phase contains spatial information, and may provide a potential neural mechanism by which temporal sequences can be coded within individual theta cycles through synaptic modification (e.g., LTP, Skaggs et al., 1996). The effect of age on this phenomenon was thus a major focus of the present study.

\section{MATERIALS AND METHODS}

\section{Animals and behavioral training}

Six pairs of young (11-12 month) and old (25-31 month) male Fischer 344 rats, obtained from the National Institute on Aging colony at Harlan Sprague Dawley, were used in this experiment (see Table 1). Rats were housed individually in Plexiglas guinea pig tubs and maintained on a 12 $\mathrm{hr}$ light/dark cycle. They were handled for a minimum of $5 \mathrm{~min} / \mathrm{d}$ for $3 \mathrm{~d}$ before entering behavioral testing. All manipulations were performed in batches of one young and one old rat. All rats underwent testing of their spatial and visual discrimination abilities on the Morris swim task (details as in Shen and Barnes, 1996). Thereafter, they were food-deprived and maintained at $\sim 85 \%$ of their ad libitum body weights. Subsequent behavioral training consisted of several steps. For the first $2-3 \mathrm{~d}$, the rats were trained to forage for randomly scattered chocolate cake sprinkles in a $62 \times 70 \mathrm{~cm}$ box for $60 \mathrm{~min} / \mathrm{d}$. They were then trained on a linear track $(122 \times 14 \mathrm{~cm})$. For the first $3 \mathrm{~d}$ on the track, rats were allowed to forage for scattered chocolate sprinkles for about $90 \mathrm{~min}$. During the subsequent week, chocolate food reward was only offered alternatively at the two ends of the track. Finally, the rats were first placed into a "nest" in the training room to rest quietly or sleep for $1 \mathrm{hr}$ and then were transferred onto the track and allowed to obtain food reward at the two ends for $30 \mathrm{~min}$. This was followed by another session in the nest in which they slept for another hour. Implantation of electrodes occurred at the end of this phase of training. The linear track described above was used only in this pretraining phase.

\section{Surgery and construction of electrodes}

The construction of the electrode assembly ("hyperdrive") has been described in detail elsewhere (Gothard et al., 1996). Briefly, the electrode array consisted of 14 independently movable "tetrodes," 12 of which were used for unit recording, one as reference for differential recordings, and the other specifically for recording EEG. Each tetrode consisted of four twisted, enamel-coated nichrome wires $(13 \mu \mathrm{m})$. The tips were goldplated, resulting in impedances at $1 \mathrm{kHz}$ in the range of $300-600 \mathrm{k} \Omega$. Each tetrode was inserted into two nested polyimide cannulas (78 and $110 \mu \mathrm{m}$ in diameter, respectively), which were themselves inserted into a 30 -gauge stainless steel cannula. The stainless steel cannula was bent at a $30^{\circ}$ angle near the end, so that the tips of all the tetrodes were placed within an area $<2 \mathrm{~mm}$ across, whereas the other ends fanned out into a cone. Each tetrode was attached to a metal screw, one turn of which equaled $\sim 320 \mu \mathrm{m}$ in depth. Each tetrode wire was attached to a contact point on a multiple pin connector plug.

National Institutes of Health guidelines were followed for all surgical procedures. Briefly, rats were anesthetized with Nembutal (sodium pentobarbital) and placed in a stereotaxic apparatus. The scalp was re- tracted, and seven or eight holes were drilled in the skull to accommodate jeweler's screws to anchor the implant. A hole was drilled over the dorsal hippocampus on the right side, at coordinates of $3.8 \mathrm{~mm}$ posterior to bregma and $2.0 \mathrm{~mm}$ lateral to the midline, into which the tetrode array was positioned and cemented in place with dental acrylic.

\section{Recording techniques and procedures}

The connector plug on the hyperdrive was attached to a head stage containing two microchips (Multichannel Concepts, Inc., Gaithersburg, $\mathrm{MD}$ ), each with 25 unity gain field effect transistor amplifiers, for impedance reduction. The signals from the head stage were carried by a multiwire cable to a set of seven, rack-mounted, eight-channel, softwarecontrolled amplifiers (Neurolynx Corp., Tucson, AZ) and then to a group of eight, 80486-based microcomputers. Signals were amplified $3000-10,000$ times, depending on signal size, and were filtered with a bandpass of $600-6000 \mathrm{~Hz}$ before being sent to analog-to-digital cards (Data Translation, Inc., Marlboro, MA) on the microcomputers. Data were acquired using Discovery software (Data Wave Inc., Broomfield, $\mathrm{CO})$. Whenever the amplitude of the spike signal exceeded a predetermined threshold, each tetrode channel acquired a $1 \mathrm{msec}$ sample of data at a rate of $32 \mathrm{KHz}$. These spike samples were time-stamped and stored on disk. Additionally, signals from one channel of each tetrode were amplified by a factor of 2000 and filtered with a bandpass of $1-100 \mathrm{~Hz}$. These additional channels were used to record EEG continuously at a sampling rate of $200 \mathrm{~Hz}$.

For tracking the movement of the animals on the behavioral apparatus, two small arrays of infrared light-emitting diodes were attached to the head stage, one extending to the front and the other to the back of the rat. Position data were acquired by a tracking device (Tracker SA-2; Dragon, Boulder, $\mathrm{CO}$ ), which extracted and stored the coordinates of the front and back diode arrays at a resolution of $256 \times 256$ pixels $(2.3$ pixels $/ \mathrm{cm}$ for the current experiment). This information was sampled at $20 \mathrm{~Hz}$. The data were later reprocessed off-line to correct or delete occasional misidentified points.

The principle of the tetrode recording technique was proposed by McNaughton et al. (1983b) as an extension of the stereotrode recording method and has subsequently been described in detail (O'Keefe and Recce, 1993; Wilson and McNaughton, 1993; Gray et al., 1995; Gothard et al., 1996). Briefly, the tips of four microwires of a tetrode are so closely spaced that most cells recorded by any of the wires will simultaneously be recorded by one or more of the other wires, typically at a different amplitude. The units, therefore, were isolated by displaying all orthogonal two-dimensional projections of the four-channel relative amplitude data and applying boundaries to each apparent unit cluster by the use of a custom interactive program running on a Sun workstation.

After the rat had recovered from surgery, the reference electrode was lowered into the corpus callosum $(\sim 1400-1600 \mu \mathrm{m}$ under the dura), and the EEG electrode was lowered into the vicinity of the hippocampal fissure to optimize recording of the theta rhythm. The other 12 tetrodes, however, were gradually lowered, over the course of a number of days, into the CA1 cell body layer of the dorsal hippocampus. During this recording optimization period, the rat was trained to run in a single direction (clockwise) on a rectangular track $(94 \mathrm{~cm} \times 40 \mathrm{~cm}, 6 \mathrm{~cm}$ in width) in the recording room for at least 20 laps. This apparatus was different from the ones used during the pretraining phase. The arrival of each tetrode into the hippocampus was recognized by several criteria, including the presence of $100-300 \mathrm{~Hz}$ "ripples" in the EEG (O'Keefe, 1976; O'Keefe and Nadel, 1978; Buzsàki et al., 1992; Ylinen et al., 1995), the polarity of "sharp waves" in the EEG (Buzsàki et al., 1986; Suzuki and Smith, 1987), and the sudden appearance, at a depth of about $2 \mathrm{~mm}$ below the dura, of large numbers of simultaneously recorded cells with complex spike discharges while the rats were in a quiet waking state. Each rat underwent two to six recording sessions. The fewer cells recorded per session, the more sessions were conducted, to get approximately equal cell sampling from each rat. Each session consisted of three phases. First, the rat was placed in a nest on top of the rectangular track and was allowed to sleep for about 30-90 min, during which recording was conducted to determine overall cell numbers. Because most cells are active during sleep, whereas many cells are silent when the rat is active in a given environment (Thompson and Best, 1989), the proportion of detectable cells with place fields on the maze could be determined using this procedure. In the second phase of the session, the rat was placed onto the rectangular track and allowed to run in the clockwise direction for 20-35 laps. Food reward was provided at two corners of the track. In the final phase, the rat was placed back into the nest to sleep again for 
A

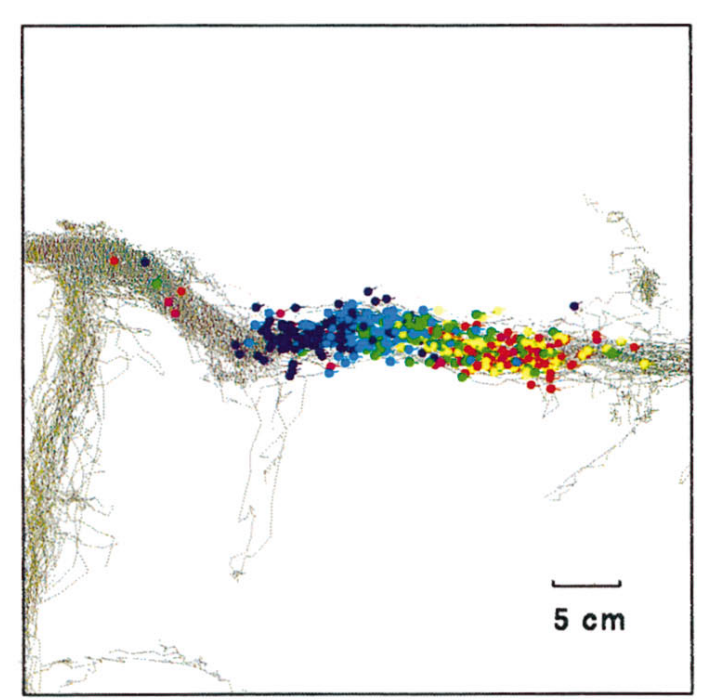

$\mathrm{C}$

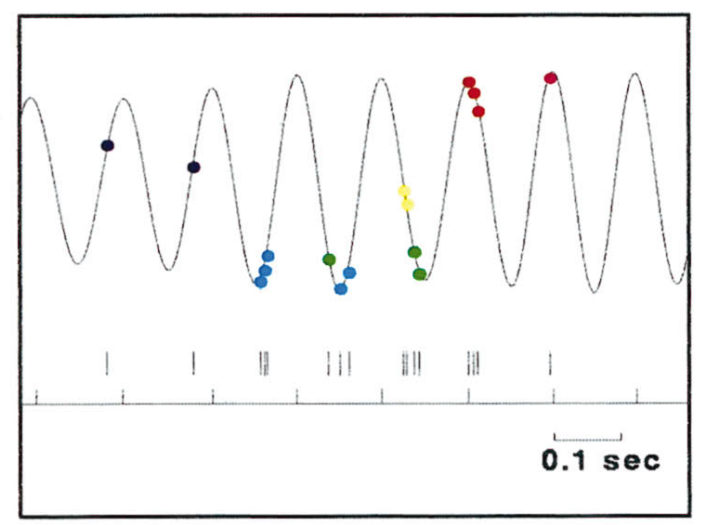

B

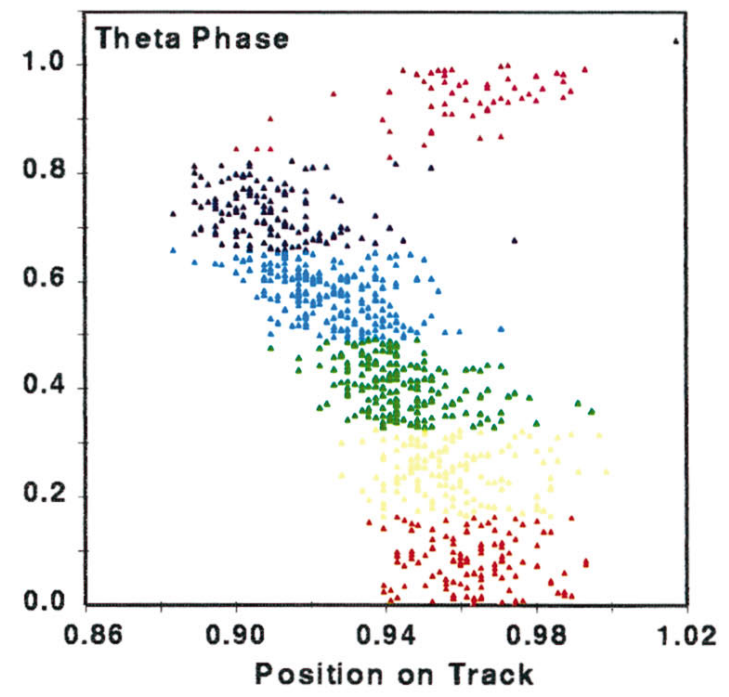

D

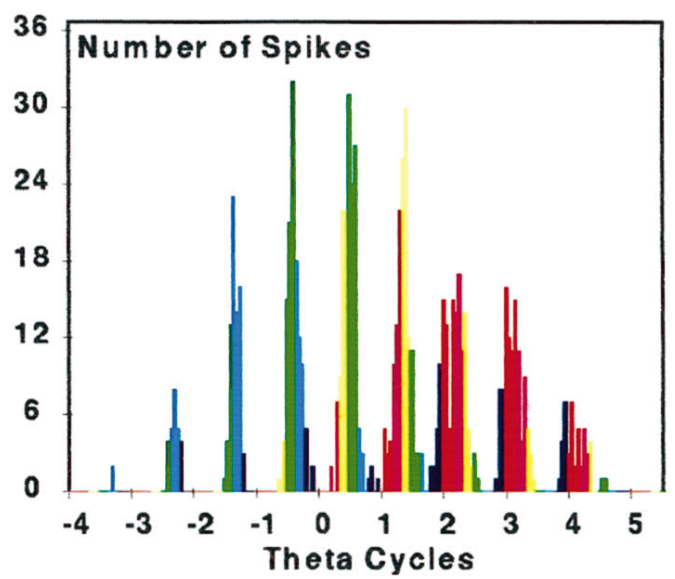

Figure 1. Illustration of the phase precession effect in the spike train of a single CA1 pyramidal cell recorded from a young rat running for food reward on a rectangular track. $A$, Spatial pattern of spike activity and firing phase. Each spike is represented by a colored dot at the corresponding location (the rat was moving in a clockwise direction around the track). The colors correspond to the theta phases indicated in $B$ and $C$. The irregular gray lines represent the rat's trajectory. Only the corner of the rectangular track containing the place field is shown. Note that, as the rat traversed the place field, the phases of the spikes advanced systematically. $B$, Theta phase of spike discharge versus position on the track. To construct this plot, the rat's position at each moment was projected onto a one-dimensional axis corresponding to the track center. Each point represents a single spike. Phase zero is the preceding peak of the theta cycle during which the spike occurred. $C$, Plot of the theta rhythm and spike train for a single traversal of the place field. The theta rhythm record was digitally filtered in the range of $6-10 \mathrm{~Hz}$. Each short vertical line below the waveform represents a single spike, and the time at which it occurred relative to the theta rhythm is labeled by a dot on the waveform. Below the spike train is a time axis, with ticks indicating the times at which the peaks of theta rhythm occurred. The period between two neighboring peaks is one theta cycle. As the rat traversed the place field, the spikes occurred earlier and earlier in the theta cycle. $D$, Histogram of activity versus theta cycle number as the rat passed through the place field over multiple trials. A point was selected on the track, near the center of the place field of the cell, and, on each pass through the field, the theta peak that occurred nearest to this point was selected as cycle zero. Near the beginning of the place field (cycle -3$)$, the spikes are distributed toward the end of the cycle. Thereafter the activity distributions shift progressively earlier.

another 30-90 min, during which time the activity of single units was also recorded.

\section{Data analysis}

Identification of units. Pyramidal cells in the CA1 region were distinguished from theta cells using standard criteria (Ranck, 1973; Fox and Ranck, 1981; Buzsàki et al., 1983; McNaughton et al., 1983a). The classification criteria for inclusion into the pyramidal cell category was that the cell must fire at least a small number of complex spike bursts during the recording session, be recorded simultaneously with other complex spike cells (in the stratum pyramidale), have a spike width (peak to valley) of at least $300 \mu \mathrm{sec}$, and have an overall mean rate of $<5 \mathrm{~Hz}$ during the behavioral recording session. To be included into the theta cell category, on the other hand, the cell would be required to fire no complex spike bursts, to have a spike width of less than $300 \mu \mathrm{sec}$, and to have a mean firing rate of $>5 \mathrm{~Hz}$ during the behavioral recording session. 
Table 1. Age of rats during recording sessions and total number of sessions conducted and included in the present study

\begin{tabular}{lllll} 
Rat & Group & Pair & Age (months) & Sessions \\
\hline 5357 & Old & $1 \mathrm{a}$ & 25.5 & 2 \\
5358 & Young & $1 \mathrm{~b}$ & 12 & 2 \\
5344 & Old & $2 \mathrm{a}$ & 25 & $1^{a}$ \\
5397 & Young & $2 \mathrm{~b}$ & 12 & 5 \\
5378 & Old & $3 \mathrm{a}$ & 29.5 & 3 \\
5397 & Young & $3 \mathrm{~b}$ & 12 & 5 \\
5408 & Old & $4 \mathrm{a}$ & 30.5 & 3 \\
5631 & Young & $4 \mathrm{~b}$ & 11.5 & 6 \\
5484 & Old & $5 \mathrm{a}$ & 30 & 4 \\
5554 & Young & $5 \mathrm{~b}$ & 12 & 4 \\
5697 & Old & $6 \mathrm{a}$ & 26.5 & 6 \\
5672 & Young & $6 \mathrm{~b}$ & 11.5 & 4 \\
\hline
\end{tabular}

${ }^{a}$ Two sessions were actually conducted, but the data from one session were corrupted because of a computer malfunction.

Quantification of theta rhythm. The EEG data were digitally filtered into the $6-10 \mathrm{~Hz}$ band. For behavioral episodes, all EEG was analyzed for periods when the animal's running velocity exceeded a predetermined threshold $(6 \mathrm{~cm} / \mathrm{sec})$, which ensured a reliable separation of theta and nontheta EEG. For rapid eye movement (REM) sleep, the presence of theta was determined by inspection (see Results). In practice, there was no difficulty in separating theta from nontheta EEG, and there was high interobserver reliability. For the analysis of age effects on theta rhythm, the velocity, theta frequency, and theta amplitude were determined every $0.2 \mathrm{sec}$. The frequency was defined as the inverse of the time between successive peaks of the filtered EEG. The amplitude for each cycle was computed as the height of the initial peak of each cycle to the baseline. Velocity was calculated every $50 \mathrm{msec}$ using a sliding window of 200 msec.

Spatial firing measures. For purposes of data analysis, the rectangular maze was "linearized" by projecting each point on the trajectory of the rat onto the nearest point on a line along the center of each arm of the track. This line was divided into 64 equal-length bins; the total occupancy time and total number of spikes were computed for each bin.

A "place field" was defined according to the criteria of Muller et al. (1987): a group of adjoining bins (sharing at least one side) with the average firing rate of each bin exceeding a specified threshold. For this study, the minimal number of adjacent bins was set at 10 , the analysis was restricted to cells with at least 100 spikes in the recording session, and the threshold was set at a constant rate of $1 \mathrm{~Hz}$. The value of $1 \mathrm{~Hz}$ was chosen because the average mean rate of all the complex spike cells firing on the maze was $\sim 1 \mathrm{~Hz}$. Although the $1 \mathrm{~Hz}$ threshold eliminated about half of the recorded spikes, these spikes were mostly those that occurred while the rat was in nontheta mode (i.e., eating, grooming, and pausing) and hence are not expected to be spatially selective. In one analysis, thresholds of 0.5 and $2 \mathrm{~Hz}$ were also used for comparison. For those cells that had more than one place field, each field was treated separately in subsequent analyses. The size of a place field was defined unidimensionally; i.e., firing locations with respect to the principle track axis were analyzed. The field rate integral was defined as the sum of the rates within the defined place field. In the subsequent analysis of place fields by laps, the field was defined as the location where spikes occurred within the field boundary as defined above, and the lap-specific field size was measured as the unidimensional distance between the first and last spikes within the field.

Phase precession analysis. After the EEG had been filtered with a bandpass of $6-10 \mathrm{~Hz}$, giving it the appearance of a gradually varying sinusoid, theta cycles were defined to begin and end at consecutive peaks of the resulting wave (Skaggs et al., 1996). Each spike that occurred in the presence of theta rhythm was assigned a nominal phase, according to the fraction of the time between the theta peaks at which it occurred. Precisely, the phase assigned to a spike at time $t$ was $\left(t-t_{0}\right) /\left(t_{1}-t_{0}\right)$, where $t_{0}$ and $t_{1}$ are the times of the preceding and following peaks of the filtered EEG signal. Note that the phase is always a number between 0 and 1 , which correspond to 0 and $360^{\circ}$, respectively. The theta phase of the spike was then plotted against the location of the animal on the track at which the spike occurred (e.g., Fig. 2A). Because phase is periodic and the entry phase of the place fields was usually somewhat after the peak of the theta cycle, the distribution of points in this plot was typically discontinuous. To examine the correlation between the phase and location, the point of discontinuity (i.e., the point at which there was an abrupt change in phase) was estimated by inspection, and $360^{\circ}$ was subtracted from the points above the discontinuity (O'Keefe and Recce, 1993). This resulted in a continuous distribution of points in the phase versus location plot (Fig. $2 B$ ). Regression analysis was then performed using a conventional least-squares minimization method (Fig. $2 B$ ), to examine the relationship between phase versus location. The entry phase and exit phase of the place field were the phases predicated by the regression line for the position of the first and the last spike of the place field, respectively. The slope, coefficient of determination $\left(r^{2}\right)$ of the regression lines, phase change (difference between the entry phase and the exit phase), and field size were averaged for each rat. The comparison between young and old rats was then conducted by animal, using one-way ANOVA.

The mean angles of the entry phase and the exit phase, which are circular (i.e., periodic) variables were calculated for each rat using:

$$
\begin{gathered}
x=\left(\cos \phi_{1}+\cos \phi_{2}+\ldots+\cos \phi_{n}\right) / n, \\
y=\left(\sin \phi_{1}+\sin \phi_{2}+\ldots+\sin \phi_{n}\right) / n, \\
\text { mean angle }=\arctan (y / x) \text { if } x>0 ; \\
180^{\circ}+\arctan (y / x) \text { if } x<0,
\end{gathered}
$$

where $n$ is the number of place fields recorded.

\section{RESULTS}

\section{Effect of age on spatial and visual discrimination behaviors}

Morris swim task

Repeated measures ANOVAs were conducted on the spatial and visual discrimination data. The old rats were significantly poorer at finding the location of the hidden platform in the water pool. Although both age groups showed improvement over trials $\left(F_{(1,23)}=2.97 ; p<0.0001\right)$, the old rats swam longer, less direct routes to it $\left(F_{(1,10)}=4.99 ; p<0.05\right)$. Both young and old rats showed improvement over trials in the visual discrimination version of the task $\left(F_{(1,11)}=1.96 ; p<0.04\right)$, with no effect of age on performance $\left(F_{(1,9)}=0.36 ; p<0.56\right)$. Thus, consistent with previous reports (e.g., Gage et al., 1984; Gallagher et al., 1985; Barnes et al., 1996) the old rats were selectively impaired, compared with young rats, on the spatial version of this task.

\section{Effect of age on theta rhythm during REM sleep}

The mean frequency and amplitude of theta rhythm during REM sleep were first compared between young and old rats. Because the rat is motionless during REM sleep, any effect of movement velocity on the theta rhythm can be ruled out in this state. Only those robust REM sessions lasting $>30 \mathrm{sec}$ were included, totaling 41 REM episodes from young rats [mean duration, $113 \pm 7$ (SEM), 54 (SD) sec] and 60 REM episodes from old rats [mean duration, $129 \pm 14$ (SEM), 87 (SD) sec]. The mean theta frequency and mean theta amplitude of each episode were then averaged for each animal by taking the frequency of REM theta rhythm calculated in blocks of $0.2 \mathrm{sec}$. These frequency blocks were averaged over the entire session to obtain the mean frequency for each session. There was no significant difference in either the theta frequency $\left(F_{(1,10)}=1.09 ; p<0.32\right)$ (Fig. $3 C$ ) or the theta amplitude $\left(F_{(1,10)}=0.02 ; p<0.89\right)$ (Fig. $\left.4 C\right)$ between young and old rats. Note that the amplitude of the theta rhythm was quite variable between individual rats of both age groups, presumably because of the fact that the amplitude is sensitive to the exact location of the EEG electrode. 

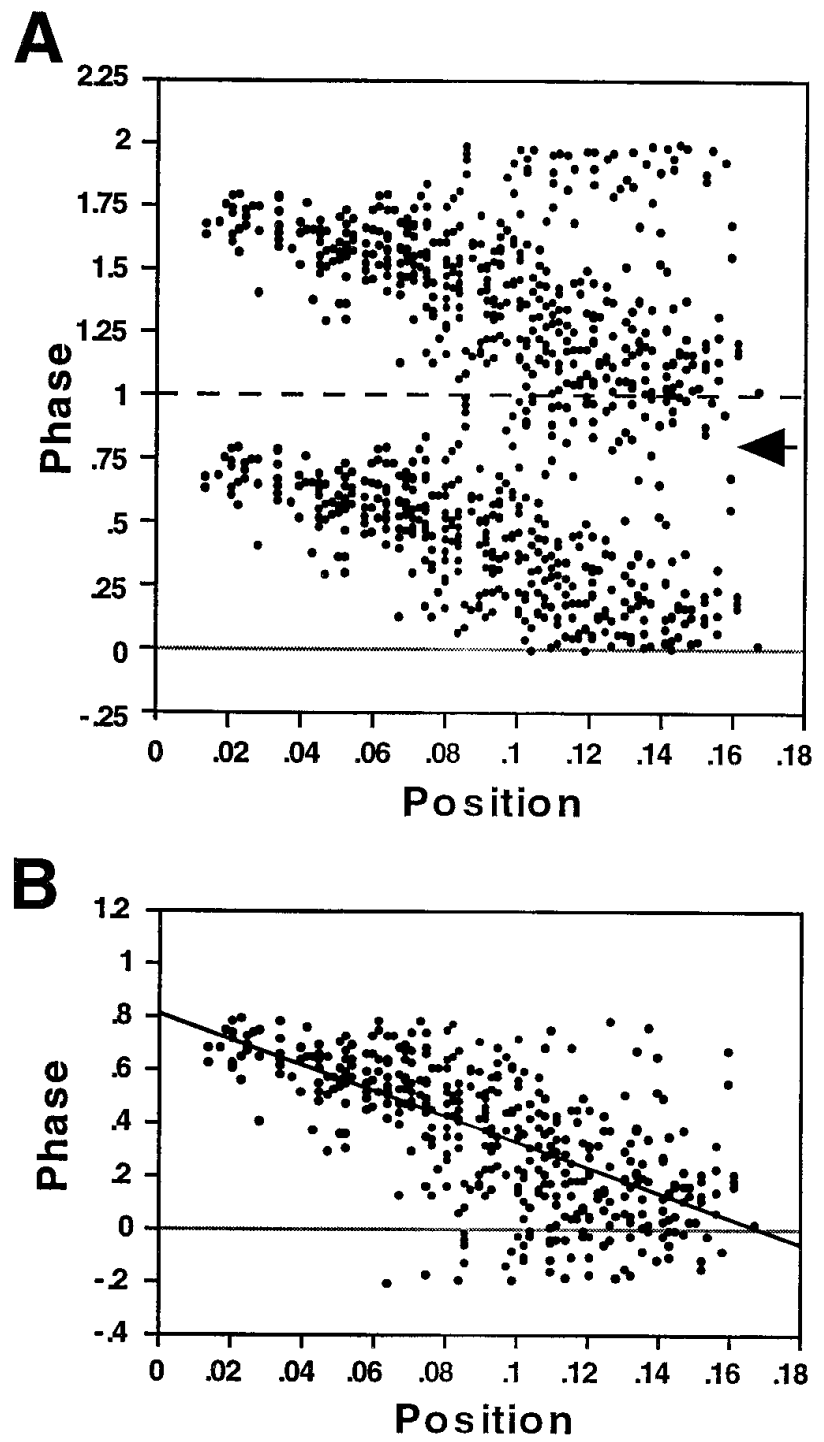

Figure 2. Illustration of the regression analysis for phase precession from one representative cell. $A$, Firing phase versus position as described in Figure $1 B$. To make the periodicity of this function clear, two cycles of phase have been plotted. The discontinuity near 0.75 (arrow) is taken to reflect the boundary between firing related to field entry and that related to field exit and serves as the reference point for performing linear regression on a single cycle of phase data. $B$, As described in Materials and Methods, the data points above the discontinuity in the plot in $A$ were replotted at the corresponding phase one cycle earlier, and a regression line was fitted using least squares minimization. As shown by Skaggs et al. (1996), firing phase typically changes nonlinearly with position, with an accelerated advance near the end of the place field; however, for the present purpose, only the linear component is considered.

\section{Effect of age on theta rhythm during behavior on the rectangular track}

There were two food reward locations on the rectangular track, at which the EEG changed from predominantly theta to large irregular activity (LIA), when the rats stopped to eat (Vanderwolf et al., 1975). Therefore, the EEG at stationary or low velocities was excluded from the data analysis, to prevent the contamination of theta rhythm by LIA. Two methods were used to achieve this: one was to eliminate measurement when the velocity was $<6$ $\mathrm{cm} / \mathrm{sec}$ (absolute velocity cutoff); the other was to eliminate the data collected in the lowest $15 \%$ of the velocity range (relative velocity cutoff). Because of the generally low running speed of old rats (see below) and their consequent longer periods on the track, the relative velocity cutoff led to a significantly larger data sample in old rats in comparison with young rats $(p<0.01)$. Only the absolute velocity cutoff data are therefore shown here, although similar results were obtained from both kinds of analysis.

For each recording session, regression and correlation analyses were used to examine the relationship between the running velocity and the frequency of theta rhythm recorded when the rat was traversing the rectangular track. Consistent with previous results (Recce, 1994), there was, in general, a weak linear relationship between the velocity and frequency, (i.e., the faster the rat ran, the higher the frequency of theta rhythm) (Fig. 3A). All 26 sessions recorded from young rats and 17 of 19 sessions recorded from old rats exhibited statistically significant correlations between the velocity and theta frequency $(p<0.05)$. The intercept and slope of the regression line for each session, as well as the correlation coefficient, were averaged for each rat, followed by one-way ANOVA analysis between young and old rats. As shown in Figure $3 C$, the intercept of the regression line in old rats was significantly smaller compared with young rats $\left(F_{(1,10)}=\right.$ 17.232; $p<0.002)$. The slope of the regression line in old rats did not differ significantly from that of young rats $(p<0.30)$ (Fig. $3 B)$. The Pearson correlation coefficient, however, was significantly lower in old rats than in young rats $\left(F_{(1,10)}=6.96 ; p<\right.$ 0.025 ) (Fig. $3 B$ ), possibly because of the reduced range of velocity in the old rats. These results are also summarized in Figure $3 A$, bottom panel, which shows that the frequency of theta rhythm in old rats was lower than that of young rats at all velocities measured. It was noted that the intercept value of the theta frequency of young rats is at the same level as the mean theta frequency during REM sleep (REM, $7.30 \pm 0.04 \mathrm{~Hz}$; maze, $7.34 \pm 0.06 \mathrm{~Hz}$ ), suggesting that this intercept value indeed reflects theta without the influence of any movement. In old rats, however, the intercept of theta frequency was slightly lower than the mean REM theta frequency (REM, $7.24 \pm 0.04 \mathrm{~Hz}$; maze, $6.959 \pm 0.07 \mathrm{~Hz}$ ). Therefore the ratio between the intercept frequency and mean frequency during REM was calculated for each animal and compared between age groups. As shown in Figure $3 D$, the ratio was about 1 in young rats and slightly $<1$ in old rats. This ratio was slightly but significantly different between the two age groups (after $\log$ transformation, $F_{(1,10)}=13.348 ; p<0.0044$ ).

The relationship between the amplitude of the theta rhythm and running velocity of the rats was also examined, using the same EEG data and regression analysis. Twenty-two of 26 sessions recorded from young rats and 17 of 19 sessions recorded from old rats exhibited significant correlations between running velocity and theta amplitude ( $p<0.05$; Fig. $4 A$ ). The intercept of regression lines was quite variable, and there was no significant difference between the two groups $\left(F_{(1,10)}=0.625 ; p<0.45\right)$ (Fig. $\left.4 C\right)$. Furthermore, there was no significant difference in the slope of regression lines between age groups $\left(F_{(1,10)}=0.226 ; p<0.64\right)$ (Fig. 4B). In addition, there was no difference in the Pearson correlation coefficient between young and old rats $\left(F_{(1,10)}=\right.$ 0.00077; $p<0.98$ ) (Fig. 4B). Because the amplitude of the theta rhythm depends on the location of EEG electrodes, the REM theta was used as the reference for each animal. The ratio between the intercept value of theta amplitude on the maze and the mean amplitude of REM theta was calculated for each rat. As shown in Figure 4, $C$ and $D$, the intercept value of the amplitude of movement-related theta rhythm was close to the theta amplitude during REM sleep in the young rats (i.e., the ratio is $\sim 1$ ). 
A
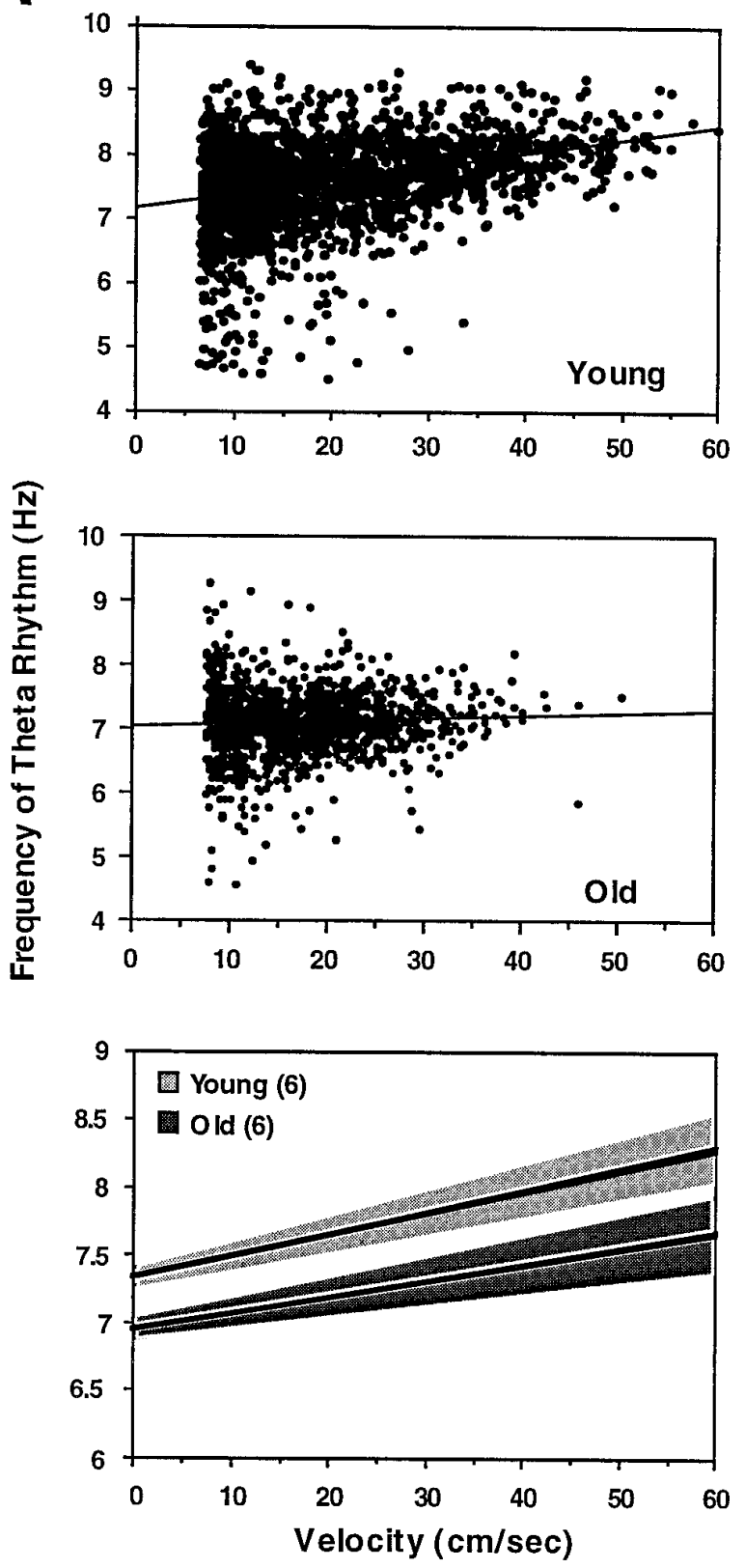

B
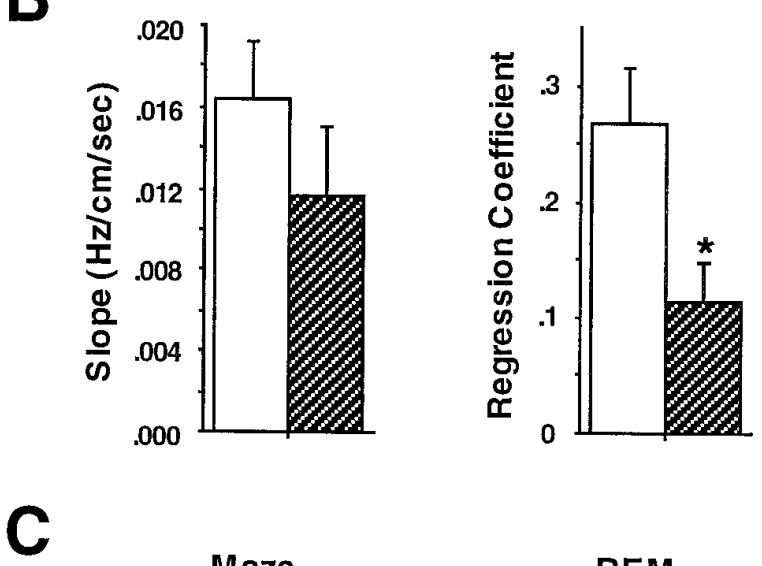

Maze

REM
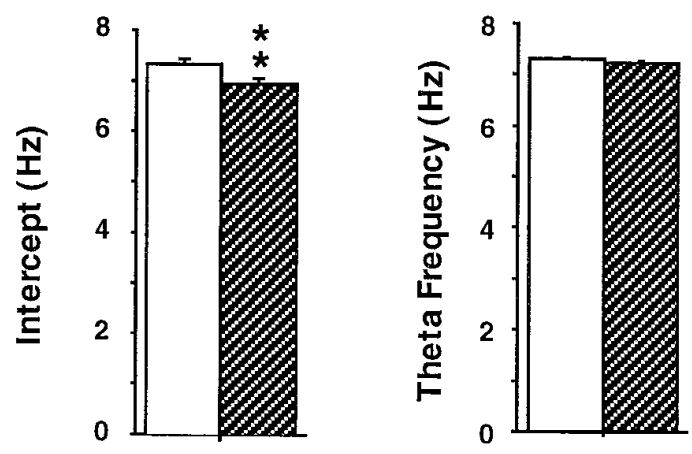

D

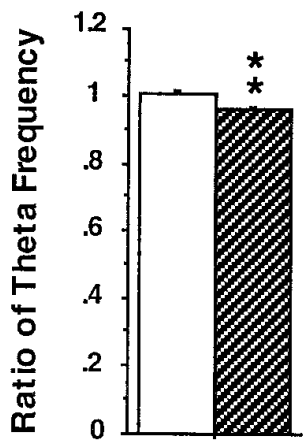

Young (6)

Old (6)

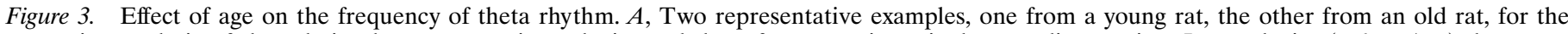

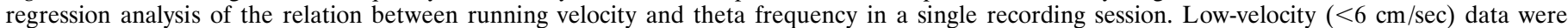

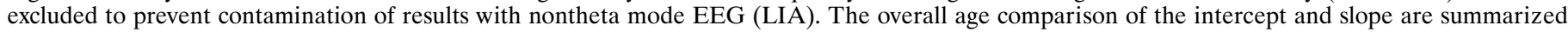

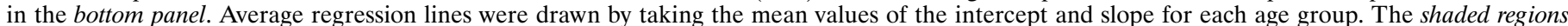

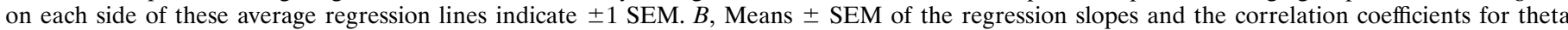

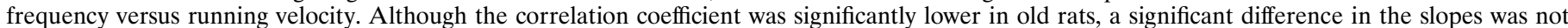

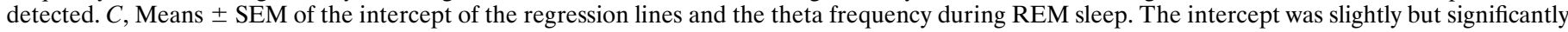

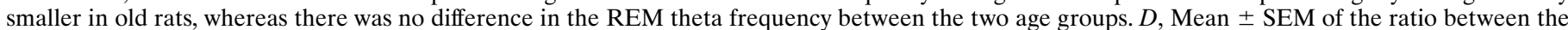

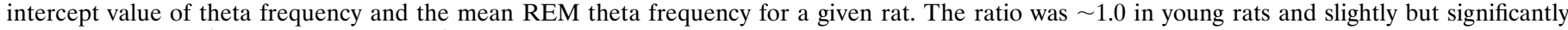
smaller in old rats $\left({ }^{*} p<0.05 ;{ }^{* *} p<0.01\right)$.

The ratio, however, was $<1.0$ in the old rats. One-way ANOVA revealed a significant difference in the ratio between the two age groups (after log transformation, $F_{(1,10)}=10.915 ; p<0.008$ ).

\section{Selection of complex spike cells}

Of the complex spike cells (young, $n=847$; old, $n=590$ ) recorded when the animals were sleeping, $57.4 \%$ of cells from young rats and $49.7 \%$ of cells from old rats had place fields on the maze (see Materials and Methods), whereas the others became virtually silent. One hundred ninety cells from young rats $(18.1 \%)$ and 84 from old rats $(12.4 \%)$ were identified as theta cells, and all of them fired during both sleep and maze sessions. A $\chi^{2}$ test for differences in proportions revealed a significant difference in the observed proportions of theta cells between the two age groups $\left(\chi^{2}=10.46 ; p<0.0014\right)$. Twelve cells recorded from young rats 


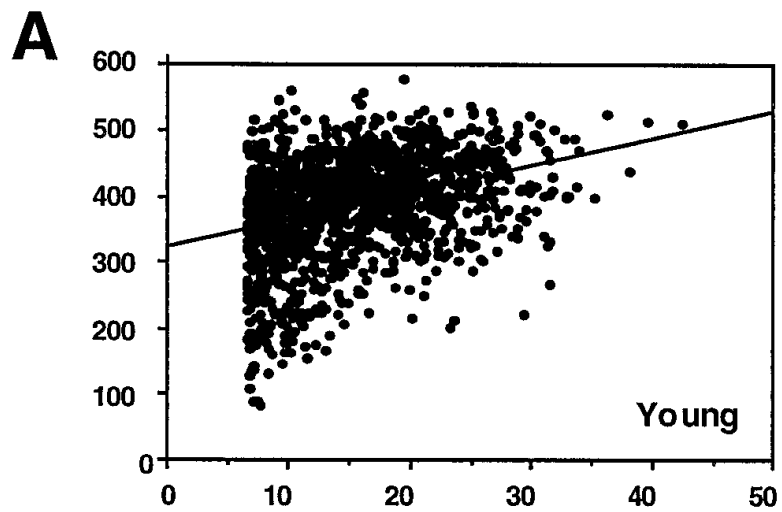

B
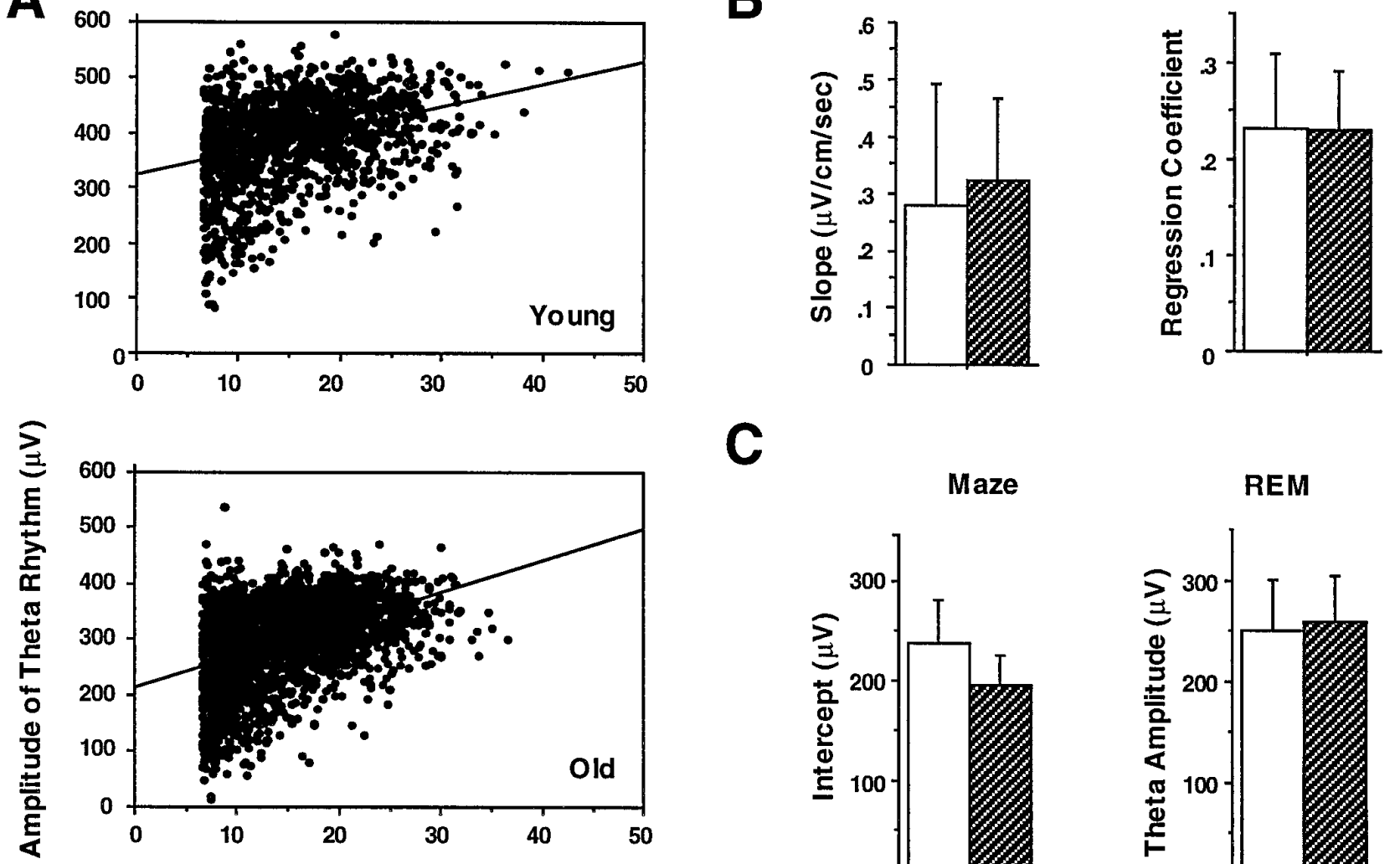

Maze
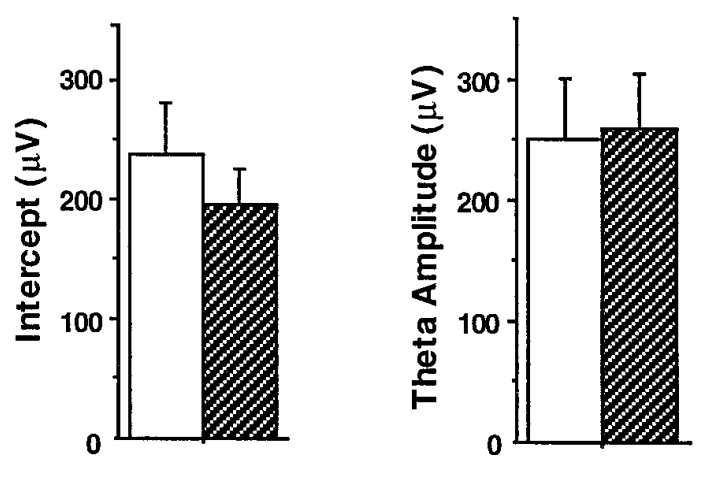

D

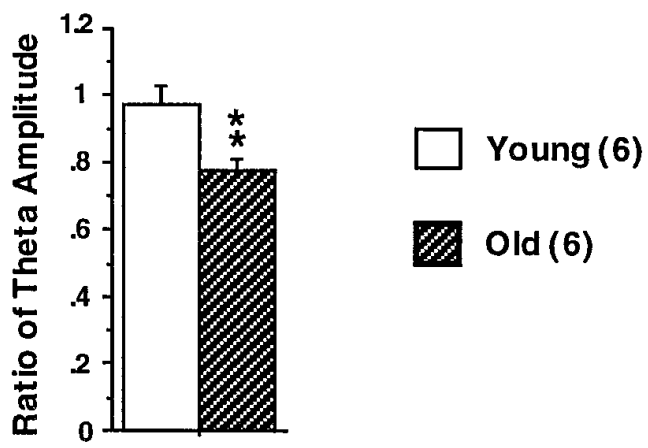

Figure 4. The effect of age on the amplitude of theta rhythm. $A$, Two examples, one from a young rat, the other from an old rat, for the regression analysis of the relation between running velocity and theta amplitude in a single recording session. The bottom panel shows the summarized data in the same way as in Figure $3 A$, except that the shaded regions representing the SEM were only drawn on one side of each line to avoid overlap. $B$, There was no significant difference between young and old rats in either the slope or the correlation coefficient. $C$, Means \pm SEM of the intercept of the regression lines and theta amplitude during REM sleep. There was no significant age effect on either measurement; however, as shown in $D$, the ratio of mean theta amplitude during REM and the amplitude intercept values during maze behavior, although $\sim 1.0$ in young rats, was significantly reduced with age $(* * p<0.01)$.

and nine cells from old rats could not be placed into either category and were not used for data analysis. Because the EEG recorded at reward locations was mostly LIA, for which theta phase is undefined, only those place fields on the part of the rectangular track other than reward locations were included for further analysis; however, those cells with multiple place fields that included both reward and nonreward locations were included in the analysis of the frequencies of multiple fields. The numbers of pyramidal cells included for analysis were 354 for young rats and 248 for old rats, as shown in Table 2. The amplitude and width of the spike waveforms of those cells with place fields on the track were similar between young and old rats (Table 3), indicating that there was no difference in the quality of unit isolation between the two age groups.

\section{The effect of age on general firing characteristics}

There was no difference between groups in the mean firing rate during either slow-wave sleep or REM sleep before the behavior on the rectangular track (Table 3 ). The mean rate during behavior on the track, however, was significantly lower in old rats than 
Table 2. Number of cells recorded from young $(n=6)$ and old $(n=6)$ rats while asleep and during behavior on the rectangular track

\begin{tabular}{|c|c|c|c|c|c|}
\hline \multirow[b]{3}{*}{ Age } & \multicolumn{3}{|c|}{ Cell types } & \multicolumn{2}{|c|}{ No. of complex spike cells } \\
\hline & \multicolumn{2}{|c|}{ Complex spike cells } & \multirow[t]{2}{*}{ Theta cells } & \multirow[b]{2}{*}{$\begin{array}{l}\text { Firing on track } \\
\text { (\% total active) }\end{array}$} & \multirow[b]{2}{*}{$\begin{array}{l}\text { Firing at food locations } \\
\text { (\% total active) }\end{array}$} \\
\hline & $\begin{array}{l}\text { No. of cells firing } \\
\text { during sleep }\end{array}$ & $\begin{array}{l}\text { No. of cells } \\
\text { on track } \\
\text { (\% active) }\end{array}$ & & & \\
\hline Young & 847 & $486(57.4)$ & 190 & $354(72.8)$ & $132(27.7)$ \\
\hline Old & 590 & $293(49.7)$ & 84 & $248(84.6)$ & $45(15.4)$ \\
\hline
\end{tabular}

${ }^{a}$ Number of cells with field locations at nonfood locations of the rectangular track versus at food locations on the track.

\begin{tabular}{lllll}
\hline \multicolumn{5}{l}{ Table 3. Firing characteristics of complex spike cells recorded from young $(\boldsymbol{n}=6)$ and old $(\boldsymbol{n}=6)$ rats } \\
& Young & Old & & \\
Cell firing property & (SEM) & $($ SEM) & $F$ & $p$ \\
\hline Amplitude $(\mu \mathrm{V})$ & $214.8(14.1)$ & $229.0(30.3)$ & 0.179 & 0.68 \\
Width (msec) & $0.34(0.011)$ & $0.34(0.013)$ & 0.031 & 0.86 \\
Mean rate in slow-wave sleep $(\mathrm{Hz})$ & $0.62(0.017)$ & $0.62(0.098)$ & 0.002 & 0.97 \\
Mean rate in REM sleep $(\mathrm{Hz})$ & $0.55(0.045)$ & $0.71(0.108)$ & 1.867 & 0.20 \\
Mean rate on maze $(\mathrm{Hz})$ & $1.11(0.083)$ & $0.81(0.103)$ & 5.007 & $0.05^{*}$ \\
Maximum rate $(\mathrm{Hz})$ & $11.93(0.61)$ & $9.05(1.32)$ & 3.930 & 0.08 \\
Field size (cm) & $30.96(1.34)$ & $23.84(2.04)$ & 8.519 & $0.02^{*}$ \\
Field rate integral $(\mathrm{cm} \times \mathrm{Hz})$ & $179.1(12.1)$ & $134.7(14.8)$ & 5.395 & $0.04^{*}$ \\
No. of fields per cell & $2.1(0.1)$ & $1.9(0.2)$ & 0.653 & 0.44
\end{tabular}

Only cells with place fields on the track are included (young, $n=354$; old, $n=248$ ).

* Statistically significant effects.

in young rats (Table 3 ). Old rats exhibited smaller place fields than young rats $\left(F_{(1,10)}=8.519 ; p<0.015\right)($ Fig. $5 A, B)$ and a smaller field rate integral $\left(F_{(1,10)}=5.395 ; p<0.04\right)$ (Table 3$)$. This age difference cannot be attributed to the threshold value $(1.0 \mathrm{~Hz})$ for determining the field size, because using either a lower $(0.5 \mathrm{~Hz})$ or higher $(2.0 \mathrm{~Hz})$ threshold, the field sizes of old rats were also significantly smaller than those of young rats $(0.5$ $\left.\mathrm{Hz}, F_{(1,10)}=9.809 ; p<0.011 ; 2.0 \mathrm{~Hz}, F_{(1,10)}=8.494 ; p<0.015\right)$ (Fig. $5 B$ ). The differences between the means of each group were similar for a given threshold cutoff value. Furthermore, in both age groups, the field size increased as the threshold value decreased. This is consistent with the previous finding of Muller et al. (1987), in which a linear relationship between field size and the logarithm of the threshold cutoff value was found. Interestingly, the ratio of field rate integral to field size was almost identical, suggesting a general broadening, rather than a mere rate increase. The maximum firing rates were not different between age groups $(p>0.05)$ (Table 3).

It is clear that some cells have more than one place field in a given environment. Therefore, the effect of age on the number of fields on the track was examined. Only $48.6 \%$ of old cells and $40.7 \%$ of young cells had single place fields. The remaining cells had two or more "place fields" as defined here. There was, however, no difference in the relative proportions of cells with a given number of fields between young and old rats (nonparametric Kolmogorov-Smirnov test, $\chi^{2}=5.716$; $p<0.11$ ) (Fig. 5C). The average number of place fields per cell was $1.9 \pm 0.2$ in old rats and $2.1 \pm 0.09$ in young rats $\left(F_{(1,10)}=\right.$ $0.653 ; p<0.44)$.

\section{Effect of age on phase precession}

The relationship between the firing phase and position within the field was examined as described in Materials and Methods. The phase precession of the majority of cells had a total phase change of $<360^{\circ}$ within a given place field, although many cells had more than one field (see Fig. 5C). A few cells (six young and six old), however, exhibited apparent double (i.e., bimodal) fields, which overlapped spatially and in which phase precession extended across two theta cycles. These cells will be described in more detail elsewhere. In these cases, the precession slope was taken as the average of the slopes within the two cycles. The mean total phase change within place fields was first averaged within rats and then within age groups.

The slopes of the regressions of phase versus location were significantly greater in old rats than in young rats $\left(F_{(1,10)}=6.654\right.$; $p<0.027$ ) (Fig. 6B). There was no difference in the total phase change over the place field between young and old rats $\left(F_{(1,10)}=\right.$ 0.092; $p<0.76$ ) (Fig. $6 C$ ). It should be noted that both the field entry phase and exit phase are values derived from the regression lines. Because of scatter about the regression line, the total phase change calculated from the difference between exit phase and entry phase is substantially $<360^{\circ}$, although the range of actual spike phase values typically approached $360^{\circ}$. There was no significant effect of age on either the entry phase (young, $230 \pm$ $8.7^{\circ}$; old, $\left.227.0 \pm 4.7^{\circ} ; U^{2}=0.116 ; p>0.20\right)$ or the exit phase (young, $12.7 \pm 20.4^{\circ}$; old, $5.27 \pm 16.1^{\circ} ; U^{2}=0.06 ; p>0.05$ ).

\section{Expansion of place fields}

It has been shown previously that place fields enlarge within a few traverses of a route even in a familiar environment (Mehta et al., 

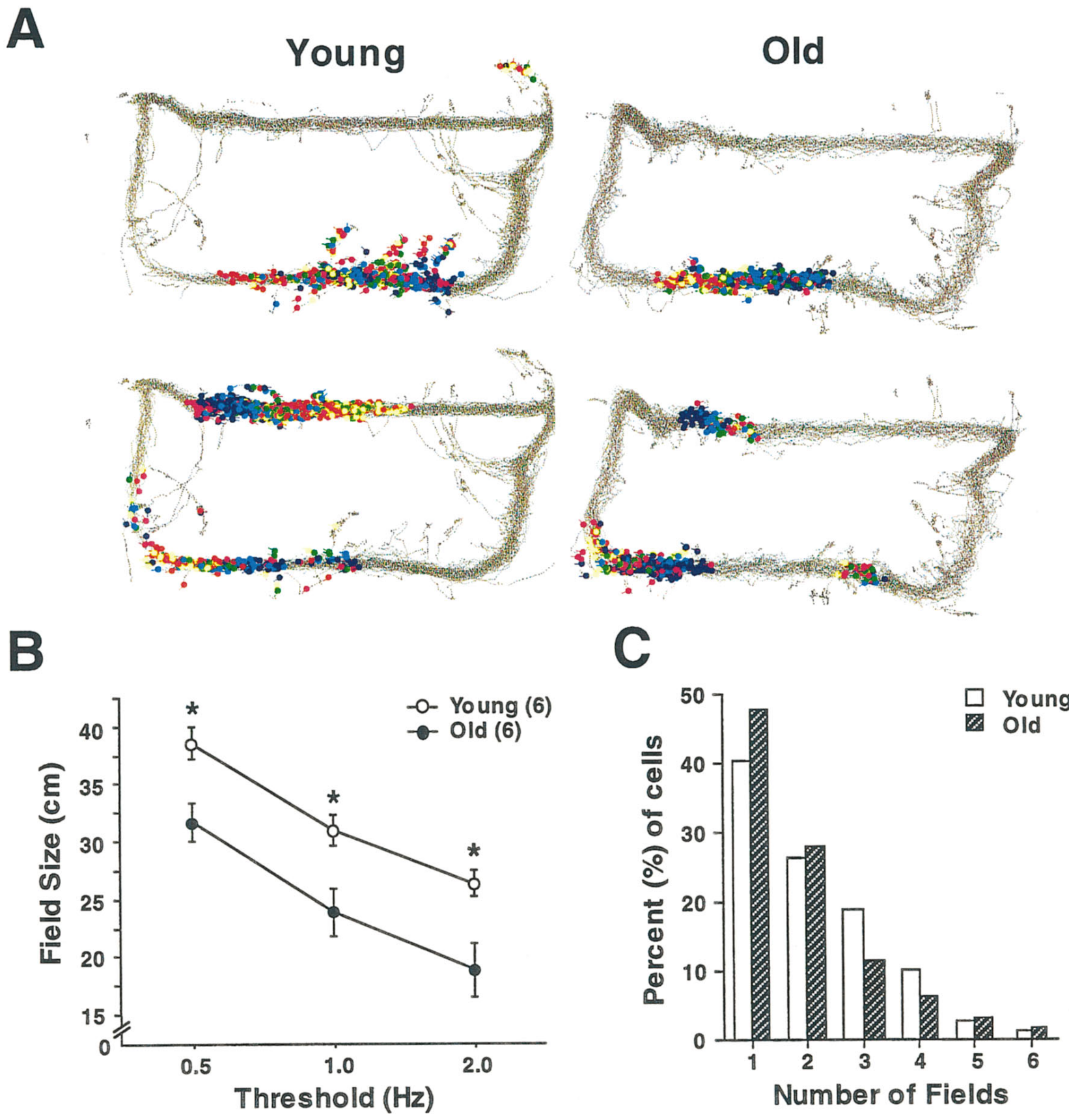

Figure 5. Effects of age on place field characteristics. $A$, Representative examples from young and old rats of data from cells with single, double, and triple place fields on the rectangular track. The individual spikes are color-coded according to firing phase as in Figure 1. $B$, Age comparison of place field sizes (computed for separate fields over the entire recording session) using different cutoff thresholds $(0.5,1.0$, and $2.0 \mathrm{~Hz}$ ). At all three thresholds, the field size of old rats was significantly smaller than that of young rats $\left({ }^{*} p<0.05\right)$. $C$, Frequency distribution (in percent) for the number of discrete place fields exhibited per cell in each age group. A place field was defined as a contiguous region of at least 10 bins with firing rates of $>1 \mathrm{~Hz}$. The distributions were approximately exponential, with no significant difference between ages. Note that the percentages are for cells with at least one field. Cells with no field are not included.

1997). The effect of age on this field expansion was also examined. The field sizes, as measured by the distance between the first and last spikes in the place field of the cell, on laps $1,5,10$, and 15 , were averaged for each animal [these points were selected on the basis of the finding of Mehta et al. (1996) that the changes in place fields saturate within a few laps]. One old animal ran $<15$ laps, thus data on lap 15 were lacking. Two-way, repeated measures ANOVA revealed a significant effect of lap $\left(F_{(3,27)}=9.247 ; p<0.0002\right)$, a significant age effect $\left(F_{(1,9)}=6.065 ; p<0.036\right)$, and a significant interaction between age and lap $\left(F_{(3,27)}=7.591 ; p<0.0008\right)$. As shown in Figure $7 A$, for the young group, the field size increased on laps 5,10 , and 15 in comparison with lap 1 . In the old group, however, the field size remained approximately the same across laps. For lap 1, there was no significant difference in the field size between the two age groups $\left(F_{(1,10)}=0.296 ; p<0.60\right)$. On the other hand, there were significant or marginally significant differ- 
A

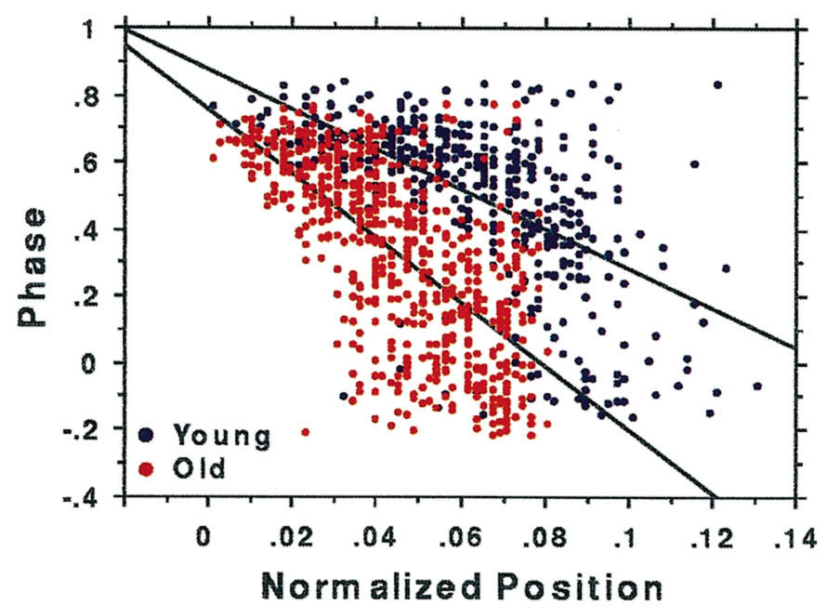

B
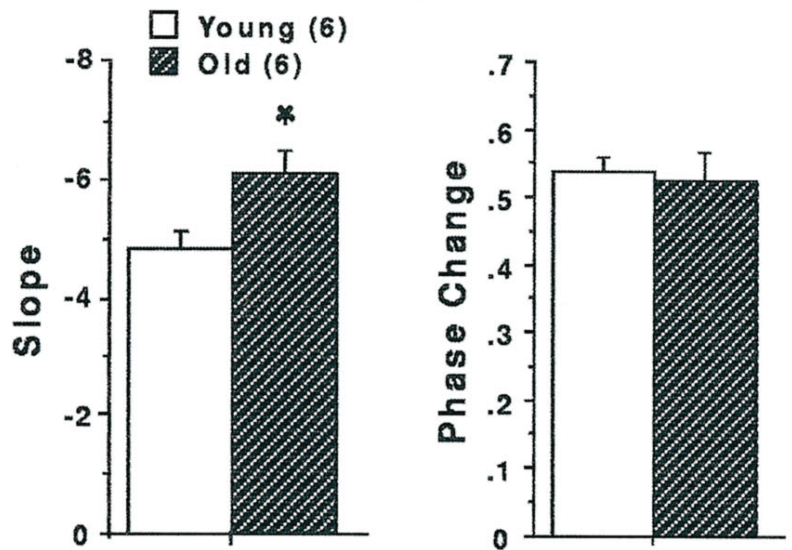

Figure 6. Effect of age on phase precession and place field size. $A$, Phase precession plots for two representative CA1 complex spike cells, one from a young rat (blue dots) and the other from an old rat (red dots). The regression lines calculated for the young cell and old cell are shown superimposed on the scatter plots. For illustration, the two fields have been aligned at the position where the first spike occurred. The $x$-axis, therefore, represents the normalized position of spike occurrence relative to that of the first spike within the field. Both fields start and end at approximately the same phase. The phase advance of the spikes recorded from the old rat, however, progresses more quickly, and the field size is correspondingly smaller (see Fig. $5 B$ ). $B$, The slope for phase versus location was significantly larger in old rats, indicating a more rapid phase precession with distance $\left({ }^{*} p<0.05\right)$. $C$, There was no difference in the total phase change of place fields between young and old. Total phase change was taken as the difference between entry and exit phases estimated from the regression analysis. There were no differences in the coefficients of determination for the regression lines $\left(r^{2}\right)$ of young and old rats.

ences in the field size on the other laps between young and old rats $\left(\operatorname{lap} 5, F_{(1,10)}=4.861 ; p<0.052 ;\right.$ lap $10, F_{(1,10)}=4.792 ; p<0.053$; lap $\left.15, F_{(1,9)}=9.79 ; p<0.012\right)$. Furthermore, the integral of firing rate within the place field of each lap was also analyzed. The field rate integral of old rats was significantly reduced compared with young rats on laps 5, 10, and 15 (lap 5, $F_{(1,10)}=6.558 ; p<0.028$; $\operatorname{lap} 10, F_{(1,10)}=19.159 ; p<0.0014$; $\left.\operatorname{lap} 15, F_{(1,10)}=6.662 ; p<0.03\right)$ (Fig. $7 C)$, but not on lap $1\left(F_{(1,10)}=3.799 ; p<0.08\right)$. There was a significant effect of lap on the field rate integral in both age groups $\left(F_{(3,37)}=9.318 ; p<0.0002\right)$. The percent increase of the field rate integral on laps 5,10 , and 15 relative to lap 1 , however, was significantly lower in old rats than in young rats (unpaired $t$ test, one-tailed, $t=1.924 ; p<0.03$ ) (Fig. 7D).

The mean value of the phases of the first and last spikes of the place field for each lap was calculated for each rat using circular statistical methods (see Eqs. 1-3 in Materials and Methods). The difference between the mean entry and mean exit phase for each lap was then calculated for each rat. A two-way ANOVA analysis revealed no effect of age $\left(F_{(1,39)}=0.587 ; p<0.45\right)$, no effect of lap $\left(F_{(3,39)}=0.378 ; p<0.77\right)$, and no significant interaction between age and lap $\left(F_{(3,39)}=0.672 ; p<0.57\right)$ on the phase change within the place field. In young rats, the lack of a significant effect of lap on the total phase change, combined with a significant effect of lap on place field size, indicates that the rate of change of phase with distance decreased across laps in young animals. Because of the small number of spikes per trial, however, it was not possible to obtain reliable slope functions for single cells on a trial by trial basis. Therefore, the slope was estimated by taking the mean difference of entry and exit phases for trials $1,5,10$, and 15 for each animal, divided by the corresponding mean field sizes. The results were compared between age groups (Fig. $7 B$ ). There was a significant effect of age on the slope for laps 5-15 $\left(F_{(1,33)}=5.513 ; p<\right.$ $0.025)$ but no effect for lap $1\left(F_{(1,10)}=0.063 ; p<0.81\right)$.

The mean running velocity for each lap was also determined. A two-way ANOVA revealed a significant effect of age on mean velocity $\left(F_{(1,39)}=35.776 ; p<0.0001\right)$ but no effect of laps $\left(F_{(3,39)}\right.$ $=0.320 ; p<0.81)$ or significant interaction between age and lap $\left(F_{(3,39)}=0.245 ; p<0.86\right)$ (Fig. $\left.7 E\right)$. Thus, the change in field size with lap number in the young rats was not attributable to any change in their running speed. There was, however, an overall effect of running speed on firing rate, as has been shown previously (McNaughton et al., 1983a). This was quantified by dividing the total number of spikes at each velocity (in $5 \mathrm{~cm} / \mathrm{sec}$ bins) by the total time spent at that velocity (Fig. $7 F$ ). For both age groups, there was a significant tendency for firing rate to increase with running speed $\left(F_{(4,40)}=72.86 ; p<0.0001\right)$; however, the relative increase was significantly less in the old animals $\left(F_{(4,40)}=\right.$ 20.34; $p<0.0001)$. Thus, the difference in mean firing rate between young and old rats cannot be accounted for by a difference in mean running velocity. The main effect of aging on place fields seems to be a failure of place field expansion during the first few passes through the field on a given day, leading to a smaller mean place field size and firing rate in old rats.

\section{DISCUSSION}

\section{Effect of age on experience-dependent place field plasticity}

The main effect that emerges from the present study is a loss of experience-dependent plasticity in the spatial firing properties of aged hippocampal pyramidal cells. Old rats failed to exhibit the expansion of place fields that normally occurs in young rats during the first few traversals of a route (even a "familiar" one) on a given day (Mehta et al., 1997). There was no difference between ages, however, in the initial size of the place fields and no significant difference in firing rate during either REM or slowwave sleep. The failure of this experience-dependent expansion provides an explanation for the earlier reports that place fields, averaged over numerous trials, tend to be smaller in old rats (Markus et al., 1994; Mizumori et al., 1996). The mechanism of the place field expansion in young animals is currently unknown. On track mazes it is asymmetric, in the sense that the expansion is predominantly in the direction opposite to the direction of motion of the rat. The firing rate near the entry point of the place 
A

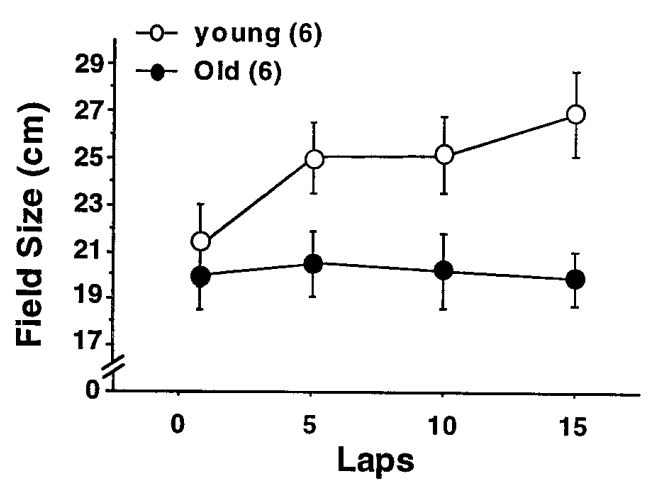

C

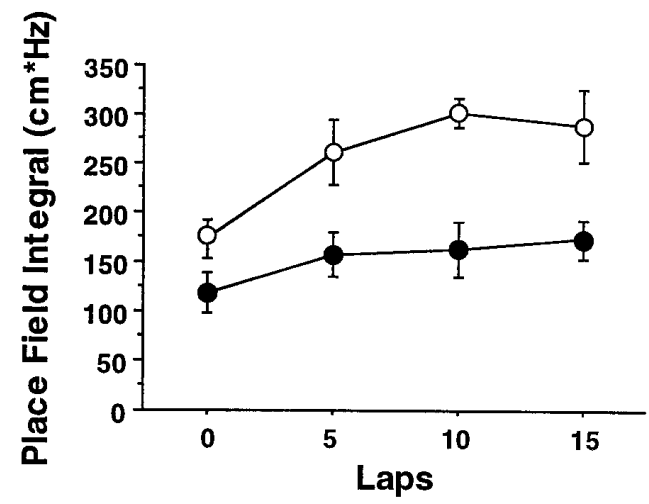

$\mathbf{E}$

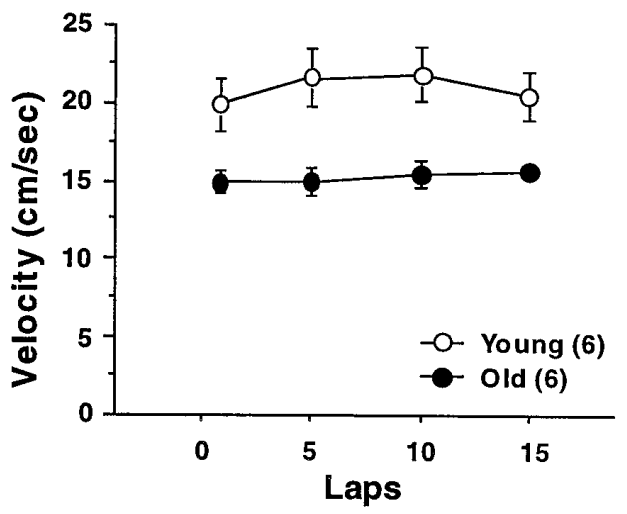

B

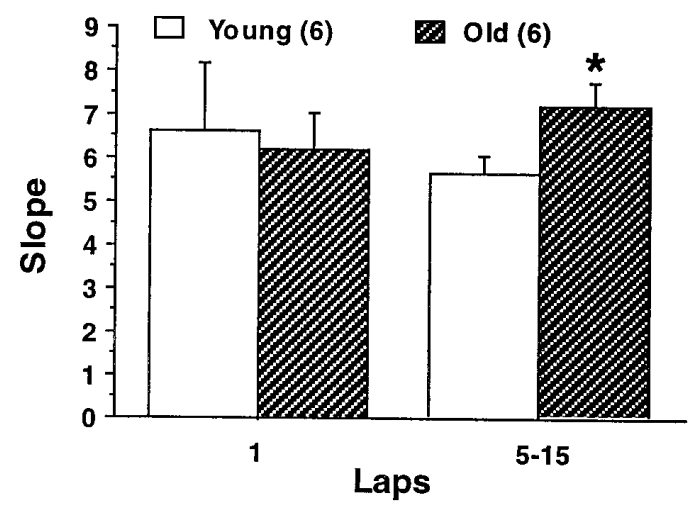

D

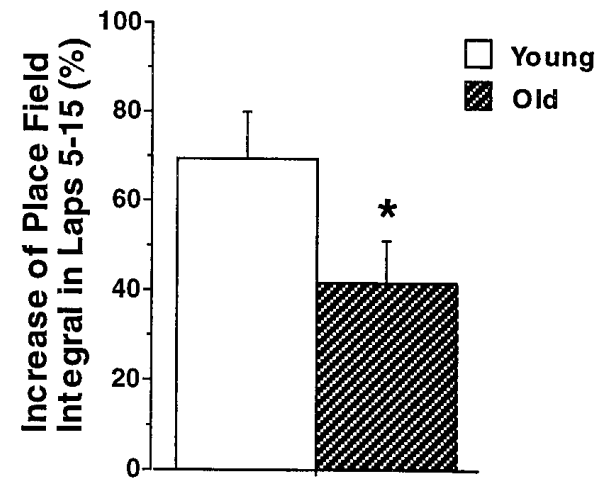

Figure 7. The effect of age on experience-dependent place field expansion as the animal traversed the rectangular track. $A$, Mean \pm SEM place field sizes for laps $1,5,10$, and 15 of young $(n=6)$ and old $(n=6)$ rats. Although the place fields of young rats expanded significantly from lap 1 to lap 5 and remained at the higher level on laps 10 and 15, those of old rats did not undergo any lap-related change. $B$, Mean \pm SEM of the slope of the phase precession as a function of lap for the two age groups. The slope was calculated by taking the mean difference of entry and exit phases for laps $1,5,10$, and 15 for each animal, divided by the corresponding mean field sizes. There was a significant effect of age on the slope for laps 5-15 $\left({ }^{*} p<0.05\right)$ but no effect for lap 1 . $C$, Mean \pm SEM integral of firing rates within the place field for laps $1,5,10$, and 15 of the two age groups. The field rate integral of old rats was significantly lower than that of young rats on laps 5, 10, and 15 but not on lap 1. D, Mean \pm SEM of the percent increase of the field rate integral on laps 5 , 10, and 15 relative to lap 1 in young and old rats. The percent increase of the field rate integral was significantly lower in old rats than in young rats $\left({ }^{*} p<0.05\right.$ ). $E$, The mean \pm SEM of the velocity through the place field for each lap for the two age groups. There was no effect of lap on the mean velocity. The velocity of old rats, however, was significantly smaller than that of young rats $(p<0.0001)$. F, Velocity-tuning curves of firing rate for young and old rats. This was quantified by dividing the total number of spikes at each velocity (in $5 \mathrm{~cm} / \mathrm{sec}$ bins) by the total time spent at that velocity. The overall velocity range of old rats was smaller than that of young rats. Although, for both age groups, there was a tendency for firing rate to increase with running velocity, the firing rate for old rats reached a lower plateau level more quickly than for young rats. The arrows indicate the mean velocities for the two age groups. 
field is thus increased, whereas there is little change in rate near the exit point (Mehta et al., 1997). This characteristic was predicted by Blum and Abbott (1996) on the basis of the temporal asymmetry of LTP induction mechanisms (Levy and Steward, 1983; Gustafsson et al., 1987; Levy, 1989). Temporal asymmetry implies that, as the rat passes through two adjacent points, $\mathrm{A}$ and $\mathrm{B}$, synapses from place cells at $\mathrm{A}$ onto place cells at $\mathrm{B}$ would be preferentially enhanced. In the model of Blum and Abbott (1996), when the animal traverses a sequence of locations, asymmetric LTP causes cells at a given location to activate subsequent cells in the sequence, before the rat actually reaches their original firing locations. This causes the fields to enlarge in the direction opposite to the animal's motion. Temporally asymmetric LTP was also invoked by Tsodyks et al. (1996) and subsequently by Jensen and Lisman (1996) to explain the theta phase precession effect. In these models, the asymmetric modification of intrinsic connections is the source of the phase precession effect itself. These models predict that, with increased asymmetric strengthening of connections, the size of the place fields should increase asymmetrically in space, but the net change in phase over the theta cycle should remain the same. This is what was observed in the young rats. As the place field expanded, there was a corresponding reduction in the rate of change of phase with position, thus keeping the net phase change constant. Thus, place field size and phase precession are strongly coupled.

It seems plausible, therefore, that the age deficit in place field expansion may be a consequence of a failure of an asymmetric, LTP-like process, although other explanations remain possible. The LTP deficit explanation is made more plausible by recent in vitro findings on age-related deficits of LTP induction (Deupree et al., 1991, 1993; Moore et al., 1993) and new evidence suggesting that such an LTP induction failure in old rats may result from a reduction in the net synaptic input in old pyramidal cells (Barnes et al., 1996). The latter effect may partly be a consequence of a reduced number of functional synaptic contacts made by a given CA3 pyramidal cell axon (Barnes et al., 1992; Barnes, 1994) or reduced temporal summation in old hippocampal cells (Rosenzweig et al., 1997). Another possibility may be the reduction in frequency potentiation that occurs in old rats during LTPinducing forms of stimulation (Landfield, 1988), which would also lead to a reduction in net dopolarization. Either of these changes might lead to a reduced cooperativity (McNaughton et al., 1978) at a given stimulus level and hence less LTP. Additionally, an age-related deficit in LTP maintenance has also been found, which is significantly correlated with a loss of spatial memory capacity (Barnes and McNaughton, 1980, 1985; deToledo-Morrell and Morrell, 1985; deToledo-Morrell et al., 1988). Nevertheless, until the expansion effect is demonstrated to be LTP-mediated, other explanations should be considered. At least one of these, however, can be excluded. It is known that the transition from quiesence to activity is accompanied by changes in brain temperature, and that this change is associated with alterations in hippocampal evoked potential waveforms (Moser et al., 1993). Three observations rule this temperature effect out as a possible source of the place field plasticity. First, Mehta et al. (1997) showed that the expansion effect occurs robustly in rats that have been running continuously for $20 \mathrm{~min}$ or more when the rats are placed on a novel track, even in cells that had expanded fields on the familiar track. Second, the expansion is directionally asymmetric, which cannot be easily explained by a mere excitability change. Finally, Erickson et al. (1991) studied carefully the effects of age on the behavior-induced, temperature-dependent change in evoked potentials. There was no difference between young and old rats.

What would be the expected functional consequence of the loss of place field expansion during experience? Paradoxically, the information transmitted by an ensemble of neurons can be substantially improved if each neuron is broadly rather than narrowly tuned (e.g., Lehky and Sejnowski, 1990; Treves et al., 1996). The lack of field broadening might thus be expected to lead to a loss of precision of the spatial code in old rats and can be interpreted as a failure of the hippocampal ensemble to increase the amount of spatial information it transmits as a consequence experience. The reason for this paradoxical effect can be understood in simple information theoretic terms. Up to a limit, the expansion of place fields increases the number of neurons with place fields that overlap at any given location. Hence, the population code for location conveys more bits of information per second as place fields expand. Consider the two extremes of infinitely compact place fields on one hand and of completely spatially uniform firing on the other. In both cases, there is no information about space transmitted by the population code. Somewhere in between these two extremes, there is an optimal size of place fields, which maximizes the information transmitted. Roughly speaking, the theoretical optimum size is reached when exactly half of the population of neurons is active at any given location. This corresponds to the case of fully distributed coding. Fully distributed coding is rarely encountered, because it is extremely inefficient from the point of view of information storage (as opposed to information transmission). Thus, systems such as the hippocampus, which are thought to be involved in Hebbian associative learning, use rather sparse coding in which only a small fraction of the cells is active at any given time (Marr, 1971; McNaughton and Morris, 1987; Rolls and Treves, 1990). In the sparse coding regime, expansion of place fields with increased overall number of spikes, as observed in young rats, would increase the information transmission.

\section{Age-related changes in hippocampal theta rhythm}

Theta rhythm frequency was slightly reduced in old rats for any given running speed. There was no age effect, however, on either the frequency or the amplitude of the theta rhythm in REM sleep. In young rats, the zero velocity intercept for both frequency and amplitude matched the corresponding values during REM sleep. In contrast, in old rats, the zero velocity intercepts for movementrelated theta differed from REM theta in both frequency $(5 \%)$ and amplitude (20\%). Interestingly, although the correlation between the theta frequency and running velocity was significantly decreased in the old rats, there was no age difference in the correlation between the theta amplitude and velocity. Thus, although theta frequency and amplitude undergo reliable agerelated changes, these alterations are subtle and state-dependent.

What could account for the differential effects of age on theta frequency and amplitude during REM sleep and movement? Activation of serotonergic projections to the medial septum or hippocampus desynchronizes and reduces the amplitude of hippocampal EEG (Macadar et al., 1974; Assaf and Miller, 1978; Maru et al., 1979; Yamamoto et al., 1979; Vertes, 1981; VanderMaelen et al., 1986; Kinney et al., 1994; Vertes et al., 1994), and lesions of cholinergic septal neurons also decrease theta amplitude (Lee et al., 1994). Thus, age-related dysfunction of serotonergic or cholinergic hippocampal projections (Potier et al., 1992; Van Luijtelaar et al., 1992; Taylor and Griffith, 1993; Venero et al., 1993; Shen and Barnes, 1996) may contribute to the effects of aging on the theta rhythm during behavior. 


\section{Effect of age on the number of hippocampal CA1 interneurons}

There was a significant $(\sim 35 \%)$ reduction in the proportion of theta cells recorded in the old rats. This is consistent with a recent report that the number of interneurons containing calbindin is significantly decreased in hippocampal CA1 of old rats (Potier et al., 1994), whereas the number of interneurons containing parvalbumin is preserved (Miettinen et al., 1993; Potier et al., 1994). Unfortunately, at present it is not possible to assign hippocampal interneurons recorded extracellularly during behavior to corresponding anatomical and neurochemical categories, nor is there yet a sufficiently clear picture of the role of the different types of interneurons in either place field dynamics or the regulation of LTP to warrant serious speculation on the functional significance of a possible loss of interneurons during aging.

\section{Summary and Conclusions}

Place field size at the beginning of a repeated, stereotyped behavioral task was not different between age groups, but the expansion of place field size that occurred in young rats after a few traversals was severely attenuated in old animals. This difference is unlikely to be related either to changes in the theta rhythm between age groups (which were very modest or nonexistent) or to alterations in the phase of theta at which single cells fired during entry to and exit from their place fields. Regardless of the exact mechanism of the attenuated place field expansion in old rats, the results suggest that the aged hippocampus fails to exhibit an experience-dependent increase in the amount of spatial information it transmits. The present results contribute to a growing body of evidence suggesting that a deficit of functional plasticity of information transmission within the hippocampus could be a major factor in age-related memory impairment.

\section{REFERENCES}

Arnolds DEAT, Lopes da Silva FH, Artink JW, Kamp A (1979) Hippocampal EEG and behavior in dog. I. Hippocampal EEG correlates of gross motor behavior. Electroencephalogr Clin Neurophysiol 46:552-570.

Assaf SY, Miller JJ (1978) The role of a raphe serotonin system in the control of septal unit activity and hippocampal desynchronization. Neuroscience 3:539-550.

Barnes CA (1979) Memory deficits associated with senescence: a neurophysiological and behavioral study in the rat. J Comp Physiol Psychol 93:74-104.

Barnes CA (1988) Spatial learning and memory processes: the search for their neurobiological mechanisms in the rat. Trends Neurosci 11:163-169.

Barnes CA (1994) Normal aging: regionally specific changes in hippocampal synaptic transmission. Trends Neurosci 17:13-18.

Barnes CA, McNaughton BL (1980) Spatial memory and hippocampal synaptic plasticity in middle-aged and senescent rats. In: Psychology of aging: problems and perspectives (Stein D, ed), pp 253-272. New York: Elsevier.

Barnes CA, McNaughton BL (1985) An age-comparison of the rates of acquisition and forgetting of spatial information in relation to long-term enhancement of hippocampal synapses. Behav Neurosci 6:563-571.

Barnes CA, McNaughton BL, O'Keefe J (1983) Loss of place specificity in hippocampal complex spike cells of senescent rat. Neurobiol Aging 4:113-119.

Barnes CA, Rao G, Foster TC, McNaughton BL (1992) Region-specific age effects of AMPA sensitivity: electrophysiological evidence for loss of synaptic contacts in hippocampal field CA1. Hippocampus 2:457-468.

Barnes CA, Rao G, McNaughton BL (1996) Functional integrity of NMDA-dependent LTP induction mechanisms across the lifespan of F344 rats. Learning Memory 3:124-137.

Bliss TVP, Gardner-Medwin AR (1973) Long-lasting potentiation of synaptic transmission in the dentate area of the unanaesthetized rabbit following stimulation of the perforant path. J Physiol (Lond) 232:357-374.

Bliss TVP, Lømo T (1973) Long-lasting potentiation of synaptic transmission in the dentate area of the anaesthetized rabbit following stimulation of perforant path. J Physiol (Lond) 232:331-356.

Blum KI, Abbott LF (1996) A model of spatial map formation in the hippocampus of the rat. Neural Comput 8:85-93.

Buzsàki G, Czopf J, Kondakor I, Kellenyi L (1986) Laminar distribution of hippocampal rhythmic slow activity (RSA) in the behaving rat: current-source density analysis, effects of urethane and atropine. Brain Res 365:125-137.

Buzsàki G, Horvath Z, Urioste R, Hetke J, Wise K (1992) High-frequency network oscillation in the hippocampus. Science 256:1025-1027.

Buzsàki G, Leung LS, Vanderwolf GH (1983) Cellular bases of hippocampal EEG in the behaving rat. Brain Res Rev 6:139-171.

deToledo-Morrell L, Morrell F (1985) Electrophysiological markers of aging and memory loss in rats. Ann NY Acad Sci 444:296-311.

deToledo-Morrell L, Morrell F, Fleming S (1984) Age dependent deficits in spatial memory are related to impaired hippocampal kindling. Behav Neurosci 98:902-907.

deToledo-Morrell L, Geinisman Y, Morrell F (1988) Age-dependent alterations in hippocampal synaptic plasticity: relation to memory disorders. Neurobiol Aging 9:581-590.

Deupree DL, Turner DA, Watters CL (1991) Spatial performance correlates with in vitro potentiation in young and aged F344 rats. Neurobiol Aging 554:1-9.

Deupree DL, Bradley J, Turner DA (1993) Age-related alterations in potentiation in the CA1 region in F344 rats. Neurobiol Aging 14:249-258.

Erickson CA, Barnes CA, McNaughton BL, Gibbons DF (1991) An age comparison of short-term exploratory modulation of rat perforant path synaptic efficacy. Soc Neurosci Abstr 17:1394.

Forbes WB, Macrides F (1984) Temporal matching of sensory-motor behavior and limbic (theta) rhythm deteriorates in aging rats. Neurobiol Aging 5:7-17.

Fox SE, Ranck Jr JB (1981) Electrophysiological characteristics of hippocampal complex spike cells and theta cells. Exp Brain Res 41:399-410.

Fox SE, Wolfson S, Ranck Jr JB (1986) Hippocampal theta rhythm and the firing of neurons in walking and urethane anesthetized rats. Exp Brain Res 62:495-508.

Gage FH, Björklund A, Stenevi U, Dunnett SB, Kelly PAT (1984) Intrahippocampal septal grafts ameliorate learning impairments in aged rats. Science 225:533-536.

Gage FH, Dunnett SB, Bjorklund A (1989) Age-related impairments in spatial memory are independent of those in sensorimotor skills. Neurobiol Aging 10:347-352.

Gallagher M, Pelleymonter MA (1988) Spatial learning deficits in old rats: a model for memory decline in the aged. Neurobiol Aging 9:549-556.

Gallagher M, Bostock E, King R (1985) Effects of opiate antagonists on spatial memory in young and aged rats. Behav Neural Biol 44:374-385.

Gothard KM, Skaggs WE, Moore KM, McNaughton BL (1996) Binding of hippocampal CA1 neural activity to multiple reference frames in a landmark-based navigation task. J Neurosci 16:823-835.

Gray CM, Maldonado PE, Wilson MA, McNaughton BL (1995) Tetrodes markedly improves the yield and reliability of multiple singleunit isolation from multi-unit recordings in cat striate cortex. J Neurosci Methods 63:43-54.

Green JD, Arduini A (1954) Hippocampal electrical activity in arousal. J Neurophysiol 17:533-557.

Gustafsson B, Wigström H, Abraham WC, Huang Y-Y (1987) Longterm potentiation in the hippocampus using depolarizing current pulses at the conditioning stimulus to single volley synaptic potentials. J Neurosci 7:774-780.

Jarrard LE (1993) On the role of the hippocampus in learning and memory in the rat. Behav Neural Biol 60:9-26.

Jensen O, Lisman JE (1996) Hippocampal CA3 region predicts memory sequence: accounting for the phase precession of place cells. Learning Memory 3:279-287.

Kinney GG, Kocsis B, Vertes RP (1994) Injections of excitatory amino acid antagonists into the median raphe nucleus produce hippocampal theta rhythm in the urethane-anesthetized rat. Brain Res 654:96-104.

Landfield PW (1988) Hippocampal neurobiological mechanisms of agerelated memory dysfunction. Neurobiol Aging 9:571-579. 
Lee MG, Chrobak JJ, Sik A, Wiley RG, Buzsàki G (1994) Hippocampal theta activity following selective lesion of the septal cholinergic system. Neuroscience 62:1022-1047.

Lehky SR, Sejnowski TJ (1990) Neural model of stereoacuity and depth interpolation based on a distributed representation of stereo disparity. J Neurosci 10:2281-2299.

Levy WB (1989) A computational approach to hippocampal function. In: computational models of learning in simple neural systems (Hawkins RD, Bower GH, eds) pp 243-305. San Diego: Academic.

Levy WB, Steward D (1983) Temporal contiguity requirements for longterm associative potentiation/depression in the hippocampus. J Neurosci 8:791-797.

Macadar AW, Chalupa LM, Lindsley DB (1974) Differentiation of brain stem loci which affect hippocampal and neocortical electrical activity. Exp Neurol 43:499-514.

Markowska AL, Olton DS, Givens B (1995) Cholinergic manipulations in the medial septal area: age-related effects on working memory and hippocampal electrophysiology. J Neurosci 15:2063-2073.

Markus EJ, Barnes CA, McNaughton BL, Gladden VL, Skaggs WE (1994) Spatial information content and reliability of hippocampal CA1 neurons: effects of visual input. Hippocampus 4:410-421.

Marr D (1971) Simple memory: a theory archicortex. Philos Trans R Soc Lond [Biol] 262:23-81.

Maru E, Takahashi LK, Iwahara S (1979) Effects of median raphe nucleus lesions on hippocampal EEG in the freely moving rat. Brain Res 163:223-234.

McFarland WL, Teitelbaum H, Hedges EK (1975) Relationship between hippocampal theta activity and running speed in the rat. J Comp Physiol Psychol 88:324-328.

McNaughton BL, Morris RGM (1987) Hippocampal synaptic enhancement and information storage within a distributed memory system. Trends Neurosci 10:408-415.

McNaughton BL, Douglas RM, Goddard GV (1978) Synaptic enhancement in fascia dentata: cooperativity among coactive afferents. Brain Res 157:277-293.

McNaughton BL, Barnes CA, O'Keefe J (1983a) The contributions of position, direction, and velocity to single unit activity in the hippocampus of freely-moving rats. Exp Brain Res 52:41-49.

McNaughton BL, O'Keefe J, Barnes CA (1983b) The stereotrode: a new technique for simultaneous isolation of several single units in the central nervous system from multiple unit records. J Neurosci Methods 8:391-397.

Mehta MR, Barnes CA, McNaughton BL (1997) Asymmetric expansion of hippocampal place fields: evidence for hebbian sequence learning. Proc Natl Acad Sci USA, in press.

Miettinen R, Sirviö J, Riekkinen PS, Laakso MP, Riekkinen M, Riekkinen PJ (1993) Neocortical, hippocampal and septal parvalbumin- and somatostatin-containing neurons in young and aged rats: correlation with passive avoidance and water maze performance. Neuroscience 53:367-378.

Mizumori SJY, Lavoie AM, Kalyani A (1996) Redistribution of place representation in the hippocampus of aged rats performing a spatial memory task. Behav Neurosci 110:1006-1016.

Moore CI, Browning MD, Rose GM (1993) Hippocampal plasticity induced by primed burst, but not long-term potentiation, stimulation is impaired in area CA1 of aged Fischer 344 rats. Hippocampus 3:57-66.

Morris RGM, Garrud P, Rawlins JNP, O'Keefe J (1982) Place navigation impaired in rats with hippocampal lesions. Nature 297:681-683.

Moser E, Mathiesen I, Andersen P (1993) Association between brain temperature and dentate field potentials in exploring and swimming rats. Science 259:1324-1326.

Muller RU, Kubie JL, Ranck Jr JB (1987) Spatial firing patterns of hippocampal complex-spike cells in a fixed environment. J Neurosci 7:1935-1950.

O'Keefe J (1976) Place units in the hippocampus of the freely moving rat. Exp Neurol 51:78-109.

O'Keefe J, Dostrovsky J (1971) The hippocampus as a spatial map. Preliminary evidence from unit activity in the freely moving rat. Brain Res 34:171-175.

O'Keefe J, Nadel L (1978) The hippocampus as a cognitive map. Oxford: Clarendon.

O’Keefe J, Recce ML (1993) Phase relationship between hippocampal place units and the EEG theta rhythm. Hippocampus 3:317-330.

Potier B, Rascol O, Jzazt F, Lamour Y, Dutar P (1992) Alterations in the properties of hippocampal pyramidal neurons in the aged rat. Neuroscience 48:793-806.

Potier B, Krzywkowski P, Lamour Y, Dutar P (1994) Loss of calbindinimmunoreactivity in CA1 hippocampal stratum radiatum and stratum lacunosum-moleculare interneurons in the aged rat. Brain Res 661:181-188.

Ranck Jr JB (1973) Studies on single neurons in dorsal hippocampal formation and septum in unrestrained rats. I. Behavioral correlates and firing repertoires. Exp Neurol 41:461-531.

Rapp PR, Rosenberg RA, Gallagher M (1987) An evaluation of spatial information processing in aged rats. Behav Neurosci 101:3-12.

Recce ML (1994) The representation of space in the rat hippocampus as revealed using new computer-based methods. Dissertation, University College, London.

Rolls ET, Treves A (1990) The relative advantages of sparse versus distributed encoding for associative neuronal networks in the brain. Network 1:407-421.

Rosenzweig ES, Rao G, McNaughton BL, Barnes CA (1997) The role of temporal summation in age-related LTP-induction deficits. Hippocampus, in press.

Shen J, Barnes CA (1996) Age-related decrease in the cholinergic slow EPSP in three hippocampal subfields. Neurobiol Aging 17:439-451.

Skaggs WE, McNaughton BL, Wilson MA, Barnes CA (1996) Theta phase precession in hippocampal neuronal populations and the compression of temporal sequences. Hippocampus 6:149-172.

Sutherland RJ, Kolb B, Whishaw IQ (1982) Spatial mapping: definitive disruption by hippocampal or medial frontal cortical damage in the rat. Neurosci Lett 31:271-276.

Suzuki SS, Smith GK (1987) Spontaneous EEG spikes in the normal hippocampus. III. Relations to evoked potentials. Electroencephalogr Clin Neurophysiol 69:541-549.

Taylor L, Griffith WH (1993) Age-related decline in cholinergic synaptic transmission in hippocampus. Neurobiol Aging 14:509-515.

Thompson LT, Best PJ (1989) Place cells and silent cells in the hippocampus of freely-behaving rats. J Neurosci 9:2382-2390.

Treves A, Barnes CA, Rolls ET (1996) Quantitative analysis of network models and of hippocampal data. In: Perception, memory and emotion: Frontiers in neuroscience (Ono T, McNaughton BL, Molotchnikoff S, Rolls ET, Nishijo H, eds) pp 567-579. Oxford: Pergamon.

Tsodyks MV, Skaggs WE, Sejnowski TJ, McNaughton BL (1996) Population dynamics and theta rhythm phase precession of hippocampal place cell firing: a spiking neuron model. Hippocampus 6:271-280.

Van Luijtelaar MGPA, Tonnaer JADM, Steinbusch HWM (1992) Aging of the serotonergic system in the rat forebrain: an immunocytochemical and neurochemical study. Neurobiol Aging 13:201-215.

VanderMaelen CP, Matheson GK, Wilderman RC, Patterson LA (1986) Inhibition of serotonergic dorsal raphe neurons by systemic and iontophoretic administration of buspirone, a non-benzodiazepine anxiolytic drug. Eur J Pharmacol 129:123-130.

Vanderwolf CH, Kramis R, Gillespie LA, Bland BH (1975) Hippocampal rhythmical slow activity and neocortical low voltage fast activity: relations to behavior. In: The hippocampus: Neurophysiology and behavior, Vol 2 (Isaacson RL, Pribram KH, eds), pp 101-128. New York: Plenum.

Venro JL, dela Roza C, Machado A, Cano J (1993) Age-related changes on monoamine turnover in hippocampus of rats. Brain Res 631:89-96.

Vertes RP (1981) An analysis of ascending brain stem systems involved in hippocampal synchronization and desynchronization. J Neurophysiol 46:1140-1159.

Vertes RP, Kinney GG, Kocsis B, Fortin WJ (1994) Pharmacological suppression of the median raphe nucleus with serotonin-1A agonists, 8-OH-DPAT and buspirone, produces hippocampal theta rhythm in the rat. Neuroscience 60:441-451.

Wallace JE, Krauter EE, Campbell BA (1980) Animal models of declining memory in the aged: short-term and spatial memory in old rats. $\mathrm{J}$ Gerontol 35:355-363.

Wilson MA, McNaughton BL (1993) Dynamics of the hippocampal ensemble code for space. Science 261:1055-1058.

Yamamoto T, Watanabe S, Oishi R, Ueki S (1979) Effects of midbrain raphe stimulation and lesion on EEG activity in rats. Brain Res Bull 4:491-495.

Ylinen A, Bragin A, Nadasdy Z, Jando G, Szabo I, Sik A, Buzsàki G (1995) Sharp wave-associated high-frequency oscillation $(200 \mathrm{~Hz})$ in the intact hippocampus: network and intracellular mechanisms. J Neurosci 15:30-46. 